2016-06-11

\title{
Competition for the International Pool of Talent
}

\author{
Haupt, Alexander
}

http://hdl.handle.net/10026.1/4958

10.1007/s00148-016-0601-4

Journal of Population Economics

Springer Science and Business Media LLC

All content in PEARL is protected by copyright law. Author manuscripts are made available in accordance with publisher policies. Please cite only the published version using the details provided on the item record or document. In the absence of an open licence (e.g. Creative Commons), permissions for further reuse of content should be sought from the publisher or author. 


\title{
Competition for the International Pool of Talent
}

\author{
by
}

\begin{abstract}
Alexander Haupt
Plymouth University, Plymouth Business School and Plymouth Graduate School of Management, Drake Circus, Plymouth PL4 8AA, United Kingdom, and CESifo, Munich, Germany e-mail: alexander.haupt@ plymouth.ac.uk
\end{abstract}

\section{Tim Krieger}

University of Freiburg, Department of Economics, Wilhelmstr. 1b, D-79085 Freiburg, Germany, and CESifo, Munich, Germany, e-mail: tim.krieger@vwl.uni-freiburg.de

\section{Thomas Lange}

acatech - National Academy of Science and Engineering, Geschäftsstelle München, Hofgartenstr. 2, D-80539 Munich, Germany, e-mail: lange@acatech.de

\section{April 2016}

This paper is accepted for publication in the Journal of Population Economics. The final publication is available at link.springer.com: http://dx.doi.org/10.1007/s00148-016-0601-4 


\title{
Competition for the International Pool of Talent
}

\author{
Alexander Haupt* Tim Krieger ${ }^{\dagger} \quad$ Thomas Lange $^{\ddagger}$
}

APRIL 2016

\begin{abstract}
Developed countries increasingly compete for a pool of talented students from developing countries. This competition induces host countries to vertically differentiate their education programmes: some countries supply a higher educational quality and charge higher tuition fees, while others provide a lower quality for lower tuition fees. This paper argues that the educational quality of high-quality countries, the national tuition fees and the quality and tuition fee differentials between the countries all increase as the income prospects for graduates in the developing countries catch up with the developed world and the number of international students grows. If foreign students become more likely to stay in their host country after graduation, the implications will be more ambiguous. In particular, an increase in educational quality can be accompanied by a decline in tuition fees. Intensified competition for international students does not necessarily disadvantage developing countries, since they might even benefit from a brain gain.
\end{abstract}

Keywords: Higher education; student mobility; vertical quality differentiation; return migration; brain gain

JEL classification: I28, F22, H87

*Plymouth University, Plymouth Business School and Graduate School of Management, Drake Circus, Plymouth, PL4 8AA, United Kingdom; E-Mail: alexander.haupt@plymouth.ac.uk; and CESifo, Munich, Germany.

${ }^{\dagger}$ University of Freiburg, Department of Economics, Wilhelmstr. 1b, D-79085 Freiburg, Germany; E-mail: tim.krieger@vwl.uni-freiburg.de; and CESifo, Munich, Germany.

$\ddagger$ acatech - National Academy of Science and Engineering, Geschäftsstelle München, Hofgartenstraße 2, 80539 Munich, Germany; E-Mail: lange@acatech.de. 
A foreign graduate from a local university is likely to be well-qualified, fluent in the local lingo and at ease with local customs.

Countries should be vying to attract such people.

(The Economist, January 30th, 2016: 10-11.)

\section{Motivation}

Higher education has become increasingly internationalised over the last decades. On the demand side, talented students increasingly aim at receiving an excellent education even if this requires being internationally mobile and studying abroad. In particular, many students from developing countries consider a degree from a university in a developed country as a chance to enhance their career prospects at home and abroad. On the supply side, university programmes increasingly accommodate the needs of foreign students in order to attract international talent. As a result, the number of international students (i.e., students enrolled outside their country of citizenship) has grown considerably over the last thirty years. Between 2000 and 2012, the number of foreign students within OECD countries has increased from 2.1 to 4.5 million (OECD 2014: 344). Asia is by far the largest sending region. Students from China and India alone constitute $22 \%$ and $6 \%$ of the students from OECD partner countries enrolled within the OECD (OECD 2015: 359).

In the host countries, the benefits from foreign students are substantial. In the short run, foreign students generate additional revenues from tuition fees and positive spillovers to domestic students and universities. In the long run, the acquisition of international students increases the future number of skilled workers, as many foreign students will continue to stay in their host countries after graduation (see, e.g., Dreher and Poutvaara 2011; Finn 2003; Rosenzweig 2008). The OECD estimates that investing in the tertiary education of foreign students yields a net public return of more than USD 127,000 $(65,000)$ for a man (woman) in present value terms, accounting for future tax revenues, social security contributions and social transfers as well as direct and indirect public costs of higher education (OECD 2015: 127). This positive effect also reflects the fact that during their studies foreign students acquire not only the necessary professional but also language and cultural skills which enable them to integrate into the labour market of the host country easily.

Recent measures of several OECD countries to promote the access of international students to the domestic labour market indicate that countries are aware of the associated benefits (see, e.g., Chaloff and Lemaitre 2009). As a result, about $25 \%$ of the foreign students in the OECD member states nowadays stay upon graduation 
in their host countries (OECD, 2011: 330). In fact, countries such as Australia, New Zealand and Japan consider attracting growing numbers of foreign students as part of a broader socio-economic development strategy (OECD 2011: 324-325).

However, the supply of talent is limited, and ability varies among international students. This gives rise to an intense competition between developed countries for the international pool of talent. Also, changes in the socio-economic environment will continue to transform this competition. Notably, the size of the pool of talent from developing countries will continue to grow over the next decades. At the same time, the share of international students who stay in their host country after graduation (i.e., the 'stay rate') is very likely to change too. Finally, major sending countries, such as China and India, will continue to catch up with the developed countries and provide better income prospects for graduates who return to these countries.

The aim of our paper is to analyse the competition between developed countries for the pool of talent from developing countries and its implications. In particular, we explore how the aforementioned changes in the socio-economic environment will alter the outcome of this international competition. This analysis will not only provide some hints about future trends in the developed countries, but also shed new light on the discussion of brain drain and brain gain.

To this end, we apply a model with duopolistic competition and vertical product differentiation. ${ }^{1}$ Two developed countries compete for a pool of students from developing countries by non-cooperatively setting educational quality and tuition fees. They aim at maximising their net benefits from educating foreign students, which includes future tax payments of those who continue to stay in the host country. In equilibrium, one country offers a high-quality education at high tuition fees and attracts the brightest students, while the other country provides a lower educational quality at low tuition fees and receives the less talented students.

More interestingly, educational quality, tuition fees and the allocation of students respond sensitively to changes in the socio-economic environment, i.e., to changes in the size of the talent pool, the stay rate and the income prospects for graduates who return to their home countries in the developing world. All three changes unambiguously increase the quality of education in the high-quality country and widen the quality gap between the two host countries. In contrast, the conclusions about tuition fees are less clear-cut. Both an enlarged pool of talent and enhanced income prospects for returning graduates raise the tuition fees in the two countries and the

\footnotetext{
${ }^{1}$ Models of oligopolistic competition with vertically differentiated products are frequently used in the literature on industrial economics. See, e.g., Gabszewicz and Thisse (1979) and Shaked and Sutton (1982) for seminal papers and section 4.4 of this paper for a further discussion.
} 
tuition fee differential. A higher stay rate of foreign students after graduation leads to ambiguous results. In this case, the tuition fees in both countries and the tuition fee differential can decline. Finally, a higher stay rate implies that a larger share of international students end up in the high-quality country. By contrast, in the case of rising income prospects for graduates in the developing world, and only in this case, the allocation of students can shift in favour of the low-quality country.

As a further important point, this paper stresses a new mechanism that causes a brain gain in the context of inter-country competition. In our basic model, the policy responses of the developed countries to an increase in the stay rate and the size of the talent pool unambiguously yield a qualitative brain gain, as the average human capital of the returning graduates increases. However, a larger stay rate also leads to a quantitative brain drain, as fewer students return to the developing regions.

Our concept of competition goes beyond the notion of mere inter-university competition for students. Rather, we consider governments as pivotal actors in the international competition for the pool of talent. As already mentioned above, countries such as Australia, New Zealand and Japan consider higher education policies that attract foreign talent as an explicit part of their socio-economic strategy. New Zealand, for instance, raised the quality of higher education and, in 2005, reduced the tuition fees for foreign students to become more competitive (OECD 2011: 325).

While governments can directly regulate tuition fees and influence the educational quality of public universities, they might find directing private universities more difficult, depending on the precise institutional circumstances. In the absence of public universities, competition between completely 'uncontrolled' private universities indeed yields some results that differ from our conclusions above, as we will argue. However, as long as public universities exist, the presence of completely 'uncontrolled' private universities need not invalidate our conclusions, as our account of the case of domestic competition between public and private universities will highlight. Finally, we explore whether, and to what extent, distinguishing between investments in specific educational quality, which is to the benefit of international students only, and general educational quality, which is to the benefit of both domestic and international students, drives our results.

Our analysis contributes to the literature on higher education policy and international competition for mobile students. For instance, Del Rey (2001) concludes that when international students return to their home countries after graduation, governments tend to underinvest in educational quality to discourage foreign students from free-riding on the domestic systems. Demange and Fenge (2010) argue that international competition for students leads to inefficient levels of educational quality, 
as attracting foreign students who partly continue to stay in the host country after graduation implies a negative externality for the country of origin. ${ }^{2}$ Our contribution differs from these two papers in three ways. Firstly, we analyse competition in both tuition fees and quality of education, while both other papers consider quality competition only. ${ }^{3}$ Expanding the policy space allows us to show, for instance, that quality levels and tuition fees can move in opposite directions if the stay rate of foreign students after graduation increases. Secondly, we analyse how the noncooperative quality levels and tuition fees vary with changes in the socio-economic environment, while the papers referred to above focus on exploring the welfare properties of non-cooperative equilibria. Thirdly, considering explicitly a pool of students from developing countries, we can derive some conclusions about the impact of international competition for talent on brain drain and brain gain.

Kemnitz (2007a) analyses how different funding schemes and different degrees of university autonomy affect the competition between universities. He applies a model with vertical product differentiation in which tuition fees and educational quality are endogenously determined, similar to the one we use. However, he considers a closed economy, while we focus on international competition for students. Thus, the questions we raise, such as effects of a higher stay rate on education policy, are naturally not part of his analysis, although the underlying model types are similar. ${ }^{4}$

Our paper also contributes to the literature on brain drain and brain gain (e.g., Beine et al. 2008; Eggert et al. 2010; Stark et al. 1997, 1998; Stark and Wang, 2002; Vidal, 1998). This literature stresses that international mobility reinforces private incentives to invest in education, and thus might increase human capital in developing countries. We show how socio-economic changes alter the education policy in the host countries of students from developing countries, and how this might increase human capital in developing countries. In this respect, the current paper is similar to Haupt et al. (2014) who analyse the relationship between the stay rate of students from developing countries, the education policy of a single developed host country and human capital in developing countries. In contrast to

\footnotetext{
${ }^{2}$ Several papers cover the effects of mobility on education systems in different but related contexts such as education policy and federalism (e.g., Büttner and Schwager, 2004; Hübner, 2012; Kemnitz, 2007b) and competition between cities and public schooling (Hoyt and Jensen, 2001). See also De Fraja and Iossa (2002), Gérard (2007), Krieger and Lange (2010), Lange (2009, 2013).

${ }^{3}$ Beine et al. (2014) provide empirical evidence for the impact of destination-specific factors on the location choice of international students. In line with our model, they show that an interaction term of tuition fees and education quality is a significant predictor of student inflows.

${ }^{4}$ Like Kemnitz (2007a), Grazzini et al. (2010) and Boadway et al. (1996) explore competition between universities or private schools within a jurisdiction.
} 
Haupt et al. (2014), the current paper explores the competition between developed countries for the international pool of talent and can thus assess, for instance, how several socio-economic changes affect the tuition fee differential across countries.

Our paper is organised as follows. In section 2, we set up the basic model. Section 3 analyses the competition between two host countries for the international pool of talent. In section 4, we explain how socio-economic changes shape education policies and student allocation. Section 5 explores the implications for the stock of human capital in developing countries. In section 6 , we consider the role of domestic students. Section 7 contains some concluding remarks.

\section{Governments and International Students}

We apply a duopoly model with vertical product differentiation. In this section, we explain its components and start by exploring student characteristics.

International Students The size of the international student population is exogenous and denoted by $N$. It represents the total demand from the Rest-of-theWorld (ROW) for education in two ex ante identical host countries 1 and 2. Each of these ROW students studies in one of the two host countries. More precisely, this 'pool of international talent' can be considered as the student population from developing countries who enrol at universities in developed countries.

The ROW students differ in their ability, denoted by $a$. The ability $a$ is uniformly distributed over the unit interval, i.e., $a \in[0,1]$. It captures the capacity to exploit the quality of higher education, as reflected by their future gross wage. This future gross wage $w$ consists of a 'graduate' base salary $\underline{w}$ and an educational quality premium $a q_{i}$, where $q_{i} \geq 0$ denotes the quality of education the individual receives in the host country $i, i=1,2$. That is, $w=\underline{w}+a q_{i}$. Ability and university quality are complementary in the production of the educational quality premium. The resulting labour income is taxed at the exogenous rate $\tau \in(0,1)$ in each of the developed countries 1 and 2 . In contrast to those who continue to stay in their host country and earn gross wage $w$, the individuals who return to their native ROW country earn gross wage $\gamma w, \gamma \in[0,1]$, which is taxed at the exogenous rate $\tau_{\text {Row }} \in(0,1)$.

Although labour incomes in the developed host countries usually exceed those in ROW (and we will assume that this is the case), there are usually non-economic reasons for foreign students to return to their home countries after graduation. Examples for such motives are failure of social integration in the host country, private and family ties to the country of origin, homesickness and problems with regard to 
the change of status from student to permanent immigrant in the host country. These non-economic motives are captured by an exogenous repatriation rate $(1-p)$. That is, with probability $p \in(0,1)$ individuals stay in their host country after graduation and receive a net wage $(1-\tau) w$. With probability $(1-p)$, they return to their native country and earn net wage $\left(1-\tau_{\text {Row }}\right) \gamma w$.

When migrating, individuals already anticipate that they will stay on in the host country only with probability $p$; however, information on whether they belong to the group of repatriates is only revealed after graduation. ${ }^{5}$ Thus, the expected net labour income of a graduate with ability $a$ is

$$
\mathrm{E}\left\{w_{a}\right\}=\varrho\left(\underline{w}+a q_{i}\right) \text {, where } \varrho:=\varrho(p, \gamma)=p(1-\tau)+(1-p)\left(1-\tau_{\text {ROW }}\right) \gamma>0 .
$$

As the two host countries represent the developed parts of the world, and as ROW stands for the developing region, the net labour income of a graduate in ROW never exceeds that in the developed countries:

Assumption $1(1-\tau)-\left(1-\tau_{R O W}\right) \gamma \geq 0$.

This assumption implies that staying in the host country after graduation is beneficial on pure income grounds. ${ }^{6}$ Only non-economic motives induce graduates to return to their native country with probability $p$, as discussed above. This economic attractiveness of the developed host countries creates the asymmetry between sending and receiving countries which is typical for brain drain models. Furthermore, we assume that the 'graduate' base salary $\underline{w}$ is sufficient to make studying abroad beneficial for all individuals in the 'pool of talent'. That is, we consider a market for higher education that is completely covered.

Governments The government of each host country sets its tuition fee for higher education $t_{i}$ and the quality of education $q_{i}$. Providing educational quality causes

\footnotetext{
${ }^{5}$ We ignore the possibility that a foreign-born graduate moves from the host country of education to the other developed country in order to work there. This assumption is not too restrictive. Firstly, after having studied several years in the host country, graduates are already (at least partly) integrated into, and attached to, their host society. Secondly, during the studies in the host country, graduates are acquiring country-specific skills which generate a higher return in the host country than in the other developed country. Thirdly, graduates usually find it easier to integrate into the labour market of the their host country than of another developed country. In addition, many host countries facilitate visa and work-permit processes if the applicant has successfully graduated from a domestic university (see Chaloff and Lamaitre, 2009).

${ }^{6}$ Note, however, that there is some variation across sending countries in terms of both the base wage and the skill premium (Rosenzweig 2006, 2008). Thus, returning home might be attractive in some cases, but not in the majority (on which we focus).
} 
variable costs per student $c\left(q_{i}\right)=\alpha q_{i}, \alpha \in[0,1]$, and fixed costs $F\left(q_{i}\right)$, where $F\left(q_{i}\right)$ is a twice continuously differentiable function with $\partial F / \partial q_{i}>0, \partial^{2} F / \partial q_{i}^{2}>0$ and $F(0)=0$. Tuition fees do not necessarily cover these costs, and need not be positive, as a country might subsidise international students.

Each government receives a net benefit, or rent, from offering higher education to international students

$$
R_{i}=\tau W_{i}+N_{i}\left[t_{i}-c\left(q_{i}\right)\right]-F\left(q_{i}\right)
$$

where $N_{i}$ and $W_{i}$ stand for the number of international students in country $i$ (with $N_{1}+N_{2}=N$ ) and the expected wage sum, or tax base, generated by the international students who continue to stay and work in country $i$, respectively. A country gains from international students, as they pay tuition fees $N_{i} t_{i}$ and generate expected tax revenues $\tau W_{i}$. These benefits are diminished by the variable and fixed costs of education $c\left(q_{i}\right)$ and $F\left(q_{i}\right)$.

Timing Decisions take place in three stages. In the first stage, the two governments simultaneously choose educational qualities $q_{1}$ and $q_{2}$. In the second stage, the two governments set tuition fees $t_{1}$ and $t_{2}$. In the third stage, ROW students decide whether to study in country 1 or in country 2, having perfect information about tuition fees and quality levels. Each government maximises its net benefit (2), and each individual maximises their expected income net of taxes and tuition fees $\varrho(\underline{w}+$ $\left.a q_{i}\right)-t_{i}$ (i.e., expected net income minus tuition fees).

Extensions Taken literally, this basic model captures most adequately competition between two countries with fairly egalitarian, publicly owned and controlled university systems. Therefore, we occasionally refer to the competition in this basic model as public competition or competition between public universities. To take account of the variety of higher education systems and the fact that the government might have limited control over private institutions, we later discuss competition between 'uncontrolled' private universities and domestic competition between private and public universities (see section 4.4). In an extension, we also incorporate domestic students into our model (see sections 6).

\section{Quality and Tuition Fee Competition}

We solve this three-stage game recursively and look for a subgame-perfect equilibrium. Hence, we begin by analysing the migration choices of the ROW students. 
Migration Decisions In the third stage, each ROW student decides whether to migrate to, and study in, country 1 or country 2 , given tuition fees $\left(t_{1}, t_{2}\right)$ and educational qualities $\left(q_{1}, q_{2}\right) \cdot{ }^{7}$ Comparing the individual net benefits $\varrho\left(\underline{w}+a q_{1}\right)-t_{1}$ and $\varrho\left(\underline{w}+a q_{2}\right)-t_{2}$ reveals that individuals choose country 2 (country 1 ) if and only if their ability $a$ is above (strictly below) the threshold value

$$
\hat{a}=\frac{t_{2}-t_{1}}{\varrho \Delta q} \text {. }
$$

where $\Delta q:=q_{2}-q_{1}$ denotes the regional quality differential.

Focusing on the case in which quality differentials across countries emerge, we assume, without loss of generality, that country 2 is the high-quality provider, i.e., $\Delta q>0$. (We explore in appendix A why $q_{2}=q_{1}$ cannot be an equilibrium.) Then, all students would obviously enrol in country 2 if the tuition fee $t_{2}$ were less than or equal to tuition fee $t_{1}$. For $t_{2}>t_{1}$, only individuals with a high ability $a \geq \hat{a}>0$ find it beneficial to study in country 2 , since their high ability allows them to exploit the higher educational quality effectively and to recoup the higher private costs of education. The other students choose the low-price study programme in country 1 . Thus, the number of international students is $N_{1}=\hat{a} N$ in the low-quality country 1 and $N_{2}=(1-\hat{a}) N$ in high-quality country 2 .

Then, the wage sums, or tax bases, of the two countries are

$$
\begin{gathered}
W_{1}=p N \int_{0}^{\hat{a}}\left(\underline{w}+a q_{1}\right) d a=p \hat{a} N\left[\underline{w}+\frac{1}{2} \hat{a} q_{1}\right], \\
W_{2}=p N \int_{\hat{a}}^{1}\left(\underline{w}+a q_{2}\right) d a=p(1-\hat{a}) N\left[\underline{w}+\frac{1}{2}(1+\hat{a}) q_{2}\right],
\end{gathered}
$$

where the threshold value $\hat{a}$ is given by (3). The sums comprise the expected number of foreign-born workers, $p \hat{a} N$ and $p(1-\hat{a}) N$, and the corresponding average labour income, $\underline{w}+\frac{1}{2} \hat{a} q_{1}$ and $\underline{w}+\frac{1}{2}(1+\hat{a}) q_{2}$. The terms $\frac{1}{2} \hat{a} q_{1}$ and $\frac{1}{2}(1+\hat{a}) q_{2}$ capture the average human capital of foreign-born workers, or educational quality premium, in country 1 and 2 .

Tuition Fee Competition Having analysed the students' migration choices, we now turn to the tuition fee competition in the second stage. Using the student demands $N_{1}$ and $N_{2}$ and the resulting wage sums $W_{1}$ and $W_{2}$, captured by (4) and (5), we rearrange the objective functions of the two governments:

$$
R_{1}=\underbrace{\hat{a} N\left\{\tau p\left[\underline{w}+\frac{1}{2} \hat{a} q_{1}\right]+t_{1}-c\left(q_{1}\right)\right\}}_{\text {variable net rent } r_{1}}-F\left(q_{1}\right),
$$

\footnotetext{
${ }^{7}$ Note that we assume that foreign students, when making their migration decision, have indeed perfect information about the levels of tuition fees and educational quality in the two host countries.
} 


$$
R_{2}=\underbrace{(1-\hat{a}) N\left\{\tau p\left[\underline{w}+\frac{1}{2}(1+\hat{a}) q_{2}\right]+t_{2}-c\left(q_{2}\right)\right\}}_{\text {variable net rent } r_{2}}-F\left(q_{2}\right) .
$$

The terms in braces capture the countries' expected variable net benefit from each student, consisting of expected future tax payments and current tuition fees less variable education costs. The last term in each line stands for the fixed costs of education.

Each government $i$ chooses the tuition fee $t_{i}$ that maximises rent $R_{i}$, thereby taking the educational qualities $\left(q_{1}, q_{2}\right)$, which were determined in the first stage, and the other government's tuition fee $t_{j}$ as given. When raising the tuition fees, government $i$ faces a trade-off. Obviously, the students who still migrate to country $i$ pay more for their education. Also, as higher fees deter students, the variable public spending on education decreases. However, fewer students pay tuition fees. Moreover, the decrease in student numbers reduces future tax revenues. Balancing these opposing effects gives country $i$ 's best response function $t_{i}^{b r}\left(t_{j} ; q_{1}, q_{2}\right)$, which follows from the first-order condition $d R_{i} / d t_{i}=0$ as long as the corresponding second-order condition is satisfied (see the proof of lemma 1 in appendix A).

Then, the equilibrium tuition fees $\left(t_{1}^{*}, t_{2}^{*}\right)$, which simultaneously solve $t_{1}^{*}=$ $t_{1}^{b r}\left(t_{2}^{*} ; q_{1}, q_{2}\right)$ and $t_{2}^{*}=t_{2}^{b r}\left(t_{1}^{*} ; q_{1}, q_{2}\right)$, are given by

$$
\begin{aligned}
& t_{1}^{*}\left(q_{1}, q_{2}\right)=\frac{\varrho\left[\varrho \Delta q-p \tau q_{1}+\alpha\left(q_{2}+2 q_{1}\right)\right]}{p \tau+3 \varrho}-p \tau \underline{w}, \\
& t_{2}^{*}\left(q_{1}, q_{2}\right)=\frac{\varrho\left[2 \varrho \Delta q-p \tau q_{1}+\alpha\left(q_{1}+2 q_{2}\right)\right]}{p \tau+3 \varrho}-p \tau \underline{w},
\end{aligned}
$$

leading to the tuition fee differential

$$
\Delta t^{*}(\Delta q):=t_{2}^{*}-t_{1}^{*}=\Omega(p, \varrho) \Delta q, \quad \text { where } \quad \Omega(p, \varrho)=\frac{\varrho(\alpha+\varrho)}{p \tau+3 \varrho}>0 .
$$

Obviously, the country that offers a higher educational quality strengthens the demand for its education system and can thus raise its tuition fees above the fee level of its competitor, thereby at least partly passing on the higher education costs.

The equilibrium tuition fees determine the equilibrium allocation of students:

$$
\hat{a}^{*}=\frac{\alpha+\varrho}{p \tau+3 \varrho}
$$

which follows directly from inserting the tuition fee differential (10) into the ability threshold (3). Importantly, the equilibrium threshold level $\hat{a}^{*}$ does not depend on the educational quality differential $\Delta q$. That is, every change in the quality differential is offset by a proportional change in the equilibrium tuition fees so that the allocation of students to the two countries remains unaltered. 
Educational Quality Competition In the first stage, government $i$ chooses the educational quality $q_{i}$ that maximises its net benefit $R_{i}$. Each government takes the quality of education abroad as given and anticipates the implication of its quality decision for the tuition fee competition in the second stage. Taking the equilibrium tuition fees (8) and (9) and the threshold value (11) into account, the marginal effect of the educational quality $q_{1} \geq 0$ on net benefit $R_{1}$ is

$$
\begin{aligned}
\frac{d R_{1}}{d q_{1}} & =\hat{a}^{*} N\left[\frac{p \tau}{2} \hat{a}^{*}+\frac{\partial t_{1}^{*}}{\partial q_{1}}-\frac{\partial c}{\partial q_{1}}\right]-\frac{\partial F}{\partial q_{1}} \\
& =\underbrace{-\frac{N}{2}(p \tau+2 \varrho) \hat{a}^{* 2}}_{d r_{1} / d q_{1}=}-\frac{\partial F}{\partial q_{1}}<0 .
\end{aligned}
$$

Since the marginal impact is always negative, the optimal educational quality of country 1 is $q_{1}^{*}=0 .{ }^{8}$ The intuition for this solution is straightforward. Any increase in the educational quality of the low-quality country not only drives up both fixed and variable costs, it also intensifies the tuition fee competition in the second stage because of the diminished quality differential. As a result, the per student benefit that accrues to country 1 declines. Consequently, the government of country 1 differentiates the educational quality as much as possible to relax the tuition fee competition.

The circumstances are different for country 2 . Its optimal educational quality $q_{2}^{*}$ is indeed positive and implicitly determined by the first-order condition ${ }^{9}$

$$
\begin{aligned}
\frac{d R_{2}}{d q_{2}} & =\left(1-\hat{a}^{*}\right) N\left[\frac{p \tau}{2}\left(1+\hat{a}^{*}\right)+\frac{\partial t_{2}^{*}}{\partial q_{2}}-\frac{\partial c}{\partial q_{2}}\right]-\frac{\partial F}{\partial q_{2}} \\
& =\underbrace{\frac{N}{2}(p \tau+2 \varrho)\left(1-\hat{a}^{*}\right)^{2}}_{d r_{2} / d q_{2}=}-\frac{\partial F}{\partial q_{2}}=0 .
\end{aligned}
$$

An increase in the quality of education in the high-quality country 2 raises the human capital of future skilled workers, leading to higher wages and higher expected tax payments. It also widens the gap between the two countries' educational systems which, in turn, weakens tuition fee competition and drives up tuition fees. Higher future tax payments and current tuition fees mean that country 2's variable benefit from each student increases, despite growing variable costs. This positive impact on the variable net rent $r_{2}$ has to be balanced against the rise in fixed costs.

\footnotetext{
${ }^{8} \mathrm{~A}$ quality level $q_{i}=0$ must not be interpreted as no quality at all. It rather means that the country's university just fulfils the minimum requirements for higher education.

${ }^{9}$ The second-order condition is fulfilled, as $d^{2} R_{2} / d q_{2}^{2}=-\partial^{2} F / \partial q_{2}^{2}<0$.
} 
Importantly, quality levels $q_{2}^{*}$ and $q_{1}^{*}$, which follow from conditions (12) and (13), can only be an equilibrium of the three-stage game if the tuition fees (8) and (9) indeed constitute an equilibrium of the second stage, which in turn requires that the corresponding second-order conditions $d^{2} R_{1} / d t_{1}^{2}<0$ and $d^{2} R_{2} / d t_{2}^{2}<0$ are satisfied. As we show in the proof of lemma 1 , the condition $d^{2} R_{2} / d t_{2}^{2}<0$ is always fulfilled, and the condition $d^{2} R_{1} / d t_{1}^{2}<0$ is satisfied for $q_{2}^{*}>q_{1}^{*}=0$ and in the larger neighbourhood of these quality levels. In fact, tuition fees (8) and (9) establish a unique equilibrium of the second stage for $q_{2}^{*}>q_{1}^{*}=0$. Thus, the educational quality levels characterised by conditions (12) and (13) are indeed a local equilibrium of the three-stage game. That is, no government can improve its net benefit by unilaterally choosing another educational quality in the larger neighbourhood of $q_{2}^{*}$ or $q_{1}^{*}$.

We summarise the equilibrium properties in lemma 1.

Lemma 1 A local equilibrium with the following properties exists. One host country of the ROW students provides a higher quality of education and charges higher tuition fees than the other host country. More precisely, $q_{2}^{*}>q_{1}^{*}=0$ and $t_{2}^{*}>t_{1}^{*}$. The highquality country attracts the brightest students from the international pool of talent, i.e., those with $a \in\left[\hat{a}^{*}, 1\right]$.

The proofs of all lemmas and propositions are relegated to appendix A.

\section{Competition in a Changing Environment}

Now we turn to the question of how a changing socio-economic environment, as highlighted in section 1, affects the international competition for the pool of talent. More specifically, we consider three scenarios: an increase in (i) the stay rate of foreign students, (ii) the income prospects of graduates in developing countries, and (iii) the size of the talent pool. We show how these changes affect educational quality, tuition fees, and the allocation of students. This analysis considers marginal socio-economic changes that marginally shift the equilibrium policies. It helps us to understand potential future trends in higher education and to assess possible consequences of these changes for the sending countries of talented students.

\subsection{Stay Rate of Foreign Students}

Technological, societal or political developments can explain changes in the stay rate of foreign students in their host countries. ${ }^{10}$ Let $\varepsilon_{\Delta q, p}:=(d \Delta q / d p)(p / \Delta q)$,

\footnotetext{
${ }^{10}$ Technological progress has led to plummeting communication and travel costs. As a result, people who work abroad can keep in touch with their relatives and friends at home more easily
} 
$\varepsilon_{\Omega, p}:=(\partial \Omega / \partial p)(p / \Omega), \varepsilon_{\Omega, \varrho}=(\partial \Omega / \partial \varrho)(\varrho / \Omega)$ and $\varepsilon_{\varrho, p}:=(\partial \varrho / \partial p)(p / \varrho)$ (recall that $\Omega$ is defined in (10)), then proposition 1 summarises the impact of an increase in the stay rate $p$ on quality levels, tuition fees and the allocation of students as follows:

Proposition 1 An increase in the stay rate of foreign students after graduation in the host countries of education

(i) raises the educational quality $q_{2}^{*}$ (i.e, $d q_{2}^{*} / d p>0$ ), but it does not affect the educational quality $q_{1}^{*}=0$ (thus, $d \Delta q^{*} / d p>0$ );

(ii) has an ambiguous effect on the tuition fees $t_{1}^{*}$ and $t_{2}^{*}$ and on the tuition fee differential $\Delta t^{*}$. In particular,

$$
\frac{d \Delta t^{*}}{d p} \gtreqless 0 \quad \Leftrightarrow \quad \varepsilon_{\Delta q, p}+\varepsilon_{\Omega, p}+\varepsilon_{\Omega, \varrho} \varepsilon_{\varrho, p} \gtreqless 0 ;
$$

(iii) raises the share of foreign students who study in the high-quality country (i.e., $\left.d\left(1-\hat{a}^{*}\right) / d p>0\right)$.

To elucidate the impact of the stay rate $p$ on the equilibrium outcome, we begin by considering a special case, which highlights the main mechanisms, and turn to the more general setting afterwards.

Special case: $\tau_{\mathrm{ROW}}=\tau$ and $\gamma=1$.

In this special case, we have $\varrho=1-\tau$. That is, the parameter $\varrho$ and thus the expected net labour income of a student $E\left\{w_{a}\right\}$ are independent of the stay rate $p$ (see (1)), also implying $\varepsilon_{\varrho, p}=0$. Consequently, the allocation of the students $\hat{a}^{*}$ only depends on the ratio of the tuition fee differential to the quality differential $\Delta t^{*} / \Delta q^{*}$. That is, there is no direct effect of the stay rate on the allocation of students, i.e., $(\partial \hat{a} / \partial \varrho)(\partial \varrho / \partial p)=0$ (see $(3))$. Then, the stay rate affects the equilibrium allocation only via its impact on the countries' policies, which we now discuss.

Educational Quality A higher stay rate $p$ causes a direct tax revenue effect on educational quality $q_{2}^{*}$. It increases the expected future tax payment of a foreign student in country 2. More importantly, as fewer students leave their host country after graduation, the positive impact of a higher educational quality on the expected per-student contribution to the future tax revenues is reinforced (i.e.,

and at lower costs. This reduces the psychological and financial burden of staying abroad after graduation, and can thus boost the stay rate of foreign students. Also, recent measures of developed countries to open up labour market access to foreign graduates contribute to higher stay rates. 
$\left.\partial^{2} W_{2}^{*} /\left(\partial q_{2}^{*} \partial p\right)>0\right)$. This strengthens country 2's incentive to invest in educational quality. It thus raises its quality level $q_{2}^{*}$.

At the same time, country 1 continues to face an incentive to differentiate its quality level from that of its opponent as much as possible in order to soften the ensuing tuition fee competition. This incentive, which is discussed in section 3, does not wither away with increasing stay rates. Therefore, country 1 sticks to its quality level $q_{1}^{*}=0$, and the quality differential $\Delta q^{*}$ widens as the stay rate $p$ increases.

Tuition Fees The impact of the stay rate on tuition fees is ambiguous. In particular, using $\Delta t^{*}=\Omega(p, \varrho(p)) \Delta q^{*}$ (see (10)) we find that

$$
\frac{d \Delta t^{*}}{d p}=\Omega \frac{\Delta q^{*}}{p}\left(\varepsilon_{\Delta q, p}+\varepsilon_{\Omega, p}+\varepsilon_{\Omega, \varrho} \varepsilon_{\varrho, p}\right),
$$

where the elasticities are defined at the beginning of this section. In our special case, the third term in the brackets vanishes as $\varepsilon_{\varrho, p}=0$. Then, the overall effect of the stay rate on tuition fees can be decomposed into two components. Firstly, there is an educational quality effect on tuition fees. The widening quality gap that follows from a higher stay rate weakens tuition fee competition. The two countries face an incentive to raise their tuition fees. This incentive is particularly strong for country 2 , which already charges higher tuition fees. It can now exploit its enhanced market power, since it provides an even higher educational quality. Consequently, the educational quality effect drives up tuition fee $t_{2}^{*}$ by more than $t_{1}^{*}$, and thus widens the tuition fee differential $\Delta t^{*}$. Formally, $\varepsilon_{\Delta q, p}>0$ captures this effect.

Secondly, there is a direct tax revenue effect on tuition fees. Students become more valuable because their expected tax payments in their host country increase with the stay rate $p$. In response, the two countries face an incentive to lower their tuition fees in order to attract more foreign students. This is particularly true for country 2. Its opportunity costs of losing students in terms of foregone tax revenues are particularly high because its students build up more human capital, and thus will receive higher wages and pay more taxes than those in country 1 . Hence, the direct tax revenue effect induces country 2 to cut its tuition fee by more than country 1 . This effect reduces the tuition fee differential. Formally, it is reflected by $\varepsilon_{\Omega, p}<0$.

The opposing educational quality effect and direct tax revenue effect are already sufficient to conclude that the impact of a higher stay rate on tuition fees and the tuition fee differential is ambiguous. More specifically, we find that

$$
\frac{d \Delta t}{d p} \gtreqless 0 \Leftrightarrow \varepsilon_{F, q} \lesseqgtr \frac{p \tau+3 \varrho}{p \tau+2 \varrho}+\frac{2(\alpha+\varrho)}{p \tau+2 \varrho-\alpha}=: \Gamma,
$$

where $\varepsilon_{F, q}:=\left(\partial^{2} F / \partial q^{2}\right) q /(\partial F / \partial q)$ stands for the elasticity of marginal fixed costs. Improving the quality of education is the more expensive, the greater is the elasticity 
$\varepsilon_{F, q}$. Hence, a high elasticity curbs the rise of educational quality $q_{2}^{*}$ in response to an increase of the stay rate $p$. This in turn weakens the educational quality effect. If the elasticity $\varepsilon_{F, q}$ exceeds the threshold level $\Gamma$, then the educational quality effect is so weak that the direct tax revenue effect dominates. Under these circumstances, the tuition fee differential declines along with tuition fees. Otherwise, the tuition fee differential increases.

Allocation of Students In response to a higher stay rate, the high-quality country 2 raises its educational quality $q_{2}^{*}$ further. This strengthens its market power in the tuition fee competition. Country 2 exploits its improved position by grabbing a larger share of the pool of talent, whose value to the host country has gone up. The low-quality country 1 loses students. Formally, a decline in the ratio of the tuition fee differential to the quality differential causes this shift in the allocation of students in favour of country 2 and at the expense of country 1.

Further Effects in the General Case We now return to our more general setting and consider a parameter $\varrho$ that can vary with the stay rate $p$ (i.e., $\varepsilon_{\varrho, p} \geq 0$ ). In this case, an expected income effect emerges in addition to the aforementioned effects. Now, the expected net labour income increases with the stay rate $\left(d \mathrm{E}\left\{w_{a}\right\} / d p>0\right)$. This positive impact of an increase in the stay rate on labour income is greater, the higher the educational quality. Thus, a rise in the stay rate reinforces the incentives to study in the high-quality country 2 , which has three implications.

Firstly, the demand for university places shifts in favour of country 2 for given policies $\left(q_{1}, q_{2}\right)$ and $\left(t_{1}, t_{2}\right)$. Thus, the expected income effect on demand reinforces the decline in the ability threshold $\hat{a}^{*}$. Secondly, facing a growing demand, country 2 finds it even more beneficial to invest in its educational quality. Thus, the expected income effect on educational quality reinforces the positive impact of the stay rate on educational quality $q_{2}^{*}$ and the quality differential $\Delta q^{*}$.

Thirdly, growing demand for university places in country 2 strengthens the incentives for country 2 to further raise its tuition fee for given quality levels $\left(q_{1}, q_{2}\right)$. This relaxes the pressure on country 1 , which is now more likely to increase its tuition fee too (note that the fees $t_{1}^{*}$ and $t_{2}^{*}$ are strategic complements, as rivals' choices often are in the case of price competition), albeit to a lesser extent than country 2. As the expected income effect on tuition fees exhibits a stronger upward pressure on $t_{2}^{*}$ than on $t_{1}^{*}$, it fosters a larger regional gap in tuition fees. Formally, $\varepsilon_{\Omega, \varrho} \varepsilon_{\varrho, p}>0$ captures this impact (see (14)). This direct effect is even reinforced, as the expected income effect drives up the quality differential, and thus strengthens the educational quality effect on tuition fees. Again, this mechanism raises tuition 
fees and the tuition fee differential. However, the overall effect of the stay rate on tuition fees and the tuition fee differential remains ambiguous.

All in all, the conclusions in the more general setting are qualitatively the same as in the special case. In particular, the educational quality $q_{2}^{*}$ and the quality differential on the one hand and the tuition fees and the tuition fee differential on the other hand can move in opposite directions, as stated in the following Corollary.

Corollary 1 If the direct tax revenue effect on tuition fees is sufficiently strong, then an increase in the stay rate of foreign students after graduation widens the educational quality gap (i.e., $d \Delta q^{*} / d p>0$ ), while the tuition fees of the two countries converge (i.e., $d \Delta t^{*} / d p<0$ ). Also, both tuition fees $t_{1}^{*}$ and $t_{2}^{*}$ fall, whereas educational quality $q_{2}^{*}$ increases.

In the special case, this outcome occurs if the elasticity condition $\varepsilon_{F, q}>\Gamma$ holds. For example, the fixed cost function $F(q)=q^{\mu}, \mu>1$, fulfils this elasticity condition as long as the parameter $\mu$ is sufficiently large. Also, if the tuition fee differential declines, then the tuition fees do so, too. ${ }^{11}$

\subsection{Income in ROW}

A feature of the present framework is that students can earn higher net wages in their host countries than in their home countries. This feature reflects the fact that the host countries represent developed countries, while ROW stands for developing regions. In this section, we consider the impact of the ROW's catching up with the developed countries in terms of graduate income, as we observe in the case of, e.g., China or India. Analytically, we capture this narrowing wage gap between developed and less developed countries by a marginal increase in $\gamma$. The following proposition summarises the resulting comparative statics.

Proposition 2 An increase in the graduate income in the home countries of the students

(i) raises the educational quality $q_{2}^{*}$ (i.e., $d q_{2}^{*} / d \gamma>0$ ), but it does not affect the educational quality $q_{1}^{*}=0$ (thus, $d \Delta q^{*} / d \gamma>0$ );

(ii) raises the tuition fees $t_{1}^{*}$ and $t_{2}^{*}$ and the tuition fee differential $\Delta t^{*}$ (i.e., $d t_{i}^{*} / d \gamma>0$ and $\left.d \Delta t^{*} / d \gamma>0\right)$

\footnotetext{
${ }^{11}$ From (8) and (9) follows that $t_{2}^{*}=2 t_{1}^{*}+p \tau \underline{w}$. Then, $d\left(t_{2}^{*}-t_{1}^{*}\right) / d p=d t_{1}^{*} / d p+\tau \underline{w}=$ $0.5\left(d t_{2}^{*} / d p+\tau \underline{w}\right)$, and thus $d\left(t_{2}^{*}-t_{1}^{*}\right) / d p<0$ implies both $d t_{1}^{*} / d p<0$ and $d t_{2}^{*} / d p<0$.
} 
(iii) has an ambiguous effect on the share of foreign students who study in the high-quality country:

$$
\frac{d\left(1-\hat{a}^{*}\right)}{d \gamma} \gtreqless 0 \quad \Leftrightarrow \quad 3 \alpha-p \tau \gtreqless 0 .
$$

A growing graduate income in ROW increases the expected net labour income. Again, this positive impact on wages is larger, the higher the educational quality. Thus, a rise in the wage parameter $\gamma$ reinforces individual incentives to study in the high-quality country 2. This expected income effect is the same in qualitative terms as the one discussed in the general case of section 4.1, and so are the implications.

Firstly, the demand for university places in the high-quality country rises for given policies $\left(q_{1}, q_{2}\right)$ and $\left(t_{1}, t_{2}\right)$. Secondly, as students become more inclined to study in the high-quality country, the government of country 2 benefits even more from investing in its educational quality (i.e., $\left.\left[\partial^{2} W_{2}^{*} /\left(\partial q_{2}^{*} \partial \varrho\right)\right] \partial \varrho / \partial \gamma>0\right)$. Again, the educational quality $q_{2}^{*}$ and the quality differential $\Delta q^{*}$ increase. (Needless to say, the quality $q_{1}^{*}=0$ is again not affected, for reasons already explained above.) Thirdly, the expected income effect directly pushes up tuition fees and the tuition fee differential, as discussed in section 4.1. This effect is again reinforced by the educational quality effect on tuition fees, as the quality differential widens.

Note that the ambiguity about the changes in tuition fees in proposition 1 is caused by the direct tax revenue effect on tuition fees, which works in favour of lower and converging fees. But exactly this effect does not have a counterpart in the current context. Therefore, proposition 2 provides an unambiguous result about tuition fees.

By contrast, the conclusion about the share of students in the high-quality country is no longer clear-cut. Without the direct tax revenue effect on tuition fees, there is no force that counteracts the rise in tuition fees and the tuition fee differential in response to a larger value of $\gamma$. Hence, the surge in the tuition fee differential, which drives students to the low-quality country, can be so drastic that it more than compensates for the rise in $\gamma$ and the induced increase in the quality differential, which pushes students to the high-quality country. Then, the share of students in the high-quality country falls in equilibrium. Otherwise, this share rises.

\subsection{Size of the Pool of Talent}

In the light of increasing international student mobility, we finally analyse how an enlarged pool of international talent affects the subgame-perfect policies and the allocation of students. 
Proposition 3 An increase in the size of the international pool of talent

(i) raises the educational quality $q_{2}^{*}$ (i.e., $d q_{2}^{*} / d N>0$ ), but does not affect the quality $q_{1}^{*}=0$ (thus, $d \Delta q^{*} / d N>0$ );

(ii) raises the tuition fees $t_{1}^{*}$ and $t_{2}^{*}$ and the tuition fee differential $\Delta t^{*}$ (i.e., $d t_{i}^{*} / d N>0$ and $\left.d \Delta t^{*} / d N>0\right)$;

(iii) has no impact on the share of students who study in the high-quality country (i.e., $\left.d\left(1-\hat{a}^{*}\right) / d N=0\right)$.

Firstly, there is a direct demand effect on the educational quality. A larger international student population raises the marginal variable rent of a quality increase in the high-quality country 2 . That is, $d^{2} r_{2} / d q_{2} d N>0$ (see (13)). As the fixed costs of quality improvements remain the same and are now divided over a greater number of students, investing in educational quality becomes more beneficial in country 2. Consequently, country 2 increases its educational quality $q_{2}^{*}$. Its opponent again leaves its quality level at $q_{1}^{*}=0$, for the same reasons as discussed above. Thus, the quality differential between the two countries increases.

Secondly, there is the educational quality effect on tuition fees. Again, a widening quality gap weakens tuition fee competition and enables both countries to charge higher fees, and leads to a larger tuition fee differential, as discussed above. Finally, as there is neither the direct tax revenue effect nor the expected income effect at work in the present scenario, each country's share of the international talent pool remains unchanged. Without the expected income effect, an increase in the size of the talent pool affects the allocation of students only indirectly through changes in policies. However, without the direct tax revenue effect, the ratio of the tuition fee differential to the educational quality differential (i.e., $\Omega$ ) remains unaltered, and thus the allocation of students (see (10)).

\subsection{Robustness and Other Forms of Competition}

Table 1 summarises the impact of the socio-economic changes analysed above. In all three scenarios, the educational quality $q_{2}^{*}$ increases and, along with it, the quality differential. The tuition fee differential and tuition fees may decline in response to a larger stay rate, but will certainly increase if the income in ROW or the size of the international pool of talent grows. Finally, the share of foreign students may decline, as the income in ROW grows, but will definitely increase if the stay rate goes up, and will remain unaffected by changes in the size of the pool of talent. 


\begin{tabular}{lccc}
\hline & Education quality & Tuition fees & Student allocation \\
\hline Increase of ... & & \\
& & & \\
... stay rate $(p \uparrow)$ & $q_{2}^{*} \uparrow, q_{1}^{*}=0$, & change of $t_{i}^{*}$ and & $\hat{a}^{*} \downarrow$ \\
& $\Delta q^{*} \uparrow$ & $\Delta t^{*}$ ambiguous & \\
& $q_{2}^{*} \uparrow, q_{1}^{*}=0$, & $t_{i}^{*} \uparrow, \Delta t^{*} \uparrow$ & change of $\hat{a}^{*}$ \\
& $\Delta q^{*} \uparrow$ & & ambiguous \\
& & & $\hat{a}^{*}$ unchanged \\
... size of talent pool $(N \uparrow)$ & $q_{2}^{*} \uparrow, q_{1}^{*}=0$, & $t_{i}^{*} \uparrow, \Delta t^{*} \uparrow$ & \\
& $\Delta q^{*} \uparrow$ & & \\
\hline
\end{tabular}

Table 1: Summary of comparative statics effects.

Our model is obviously a variation of the class of models with vertical product differentiation in the spirit of the seminal papers by, for instance, Gabszewicz and Thisse (1979) and Shaked and Sutton (1982). In contrast to the applications of this model type in industrial economics, however, our competitors are not firms which only focus on their private benefits but entities whose objective functions include public benefits. ${ }^{12}$ To better understand how tax revenues as a component of the objective function affect our conclusions, we now briefly sketch the competition between two universities which consider international students only as an additional income source and simply maximise the revenues from tuition fees net of education costs, i.e., $R_{i}^{P}=N_{i}\left[t_{i}-c\left(q_{i}\right)\right]-F\left(q_{i}\right)$, perhaps to subsidise research. We refer to this case, which is as close as possible to that in traditional models of industrial economics, as private competition, as public benefits are not taken into account, and denote it by the superscript $P$.

If universities ignore the fiscal externalities of foreign students, they are less incentivised to invest in their students' human capital to attract students in the first place. As a result, the educational quality $q_{2}$ and the quality differential $\Delta q$ are lower, while the tuition fees of both universities $t_{1}$ and $t_{2}$ might still be higher under private competition than under public competition. More interestingly, replacing public with private competition affects several of our comparative statics results.

Consider the impact of a change in the stay rate, as summarised in proposition 1. Under private competition, the direct tax revenue effect on quality $q_{2}$, which is explored in section 4.1, does not occur any more, since the private universities do

\footnotetext{
${ }^{12}$ Another application of this type of model to public economics is Zissimos and Wooders (2008), who analyse tax competition.
} 
not pay attention to the fact that a higher stay rate $p$ raises the positive impact of educational quality on future tax payments. By contrast, the expected income effect on educational quality is still at work. That is, as a higher stay rate increases the students' expected income gains from educational quality, and thus raises their willingness to pay for quality, the high-quality university improves its quality. However, this positive expected income effect also vanishes in the special case with $\tau_{\text {Row }}=\tau$ and $\gamma=1$, as discussed in section 4.1. Thus, while educational quality $q_{2}^{P}$ still tends to increase with the stay rate $p$, this positive relationship is somewhat weaker than under public competition. In particular, an increase in the stay rate $p$ has no effect at all on quality $q_{2}^{P}$ in the special case with $\tau_{\mathrm{Row}}=\tau$ and $\gamma=1$.

A higher expected income as a result of a higher stay rate directly and indirectly (through its impact on educational quality) drives up tuition fees and the tuition fee differential, as analysed in section 4.1. Under public competition, the expected income and educational quality effects on tuition fees are counteracted by the direct tax revenue effect, i.e., public universities will face an incentive to lower their tuition fees if international graduates are more likely to stay on in their host country as tax payers. In the case of private universities, the direct tax revenue effect does obviously not occur, and we are left with the two other effects. Consequently, and unlike the result in proposition 1 , the tuition fees $t_{1}^{P}$ and $t_{2}^{P}$ and the tuition fee differential $\Delta t^{P}$ weakly increase with the stay rate $p$. As an immediate implication, corollary 1 does not hold true any more.

These differences between public and private competition still arise when we apply a more general and realistic model of competition between private universities in which private universities receive a prestige benefit from well-educated alumni and potentially provide a higher educational quality than public universities would do. We show this result and how private competition changes our other propositions in an additional appendix.

In this additional appendix $\mathrm{B}$, we also analyse the case of domestic competition between a public and a private university. This further form of competition is important because many international students might have regional preferences and favour studying in one country over doing so in another. In this case, universities within a country are in fiercer competition with each other than universities in different countries, and some of these domestic universities might be public institutions while others might be private ones. Surprisingly, our propositions and the corollary prove to be fairly robust with respect to replacing international with domestic competition. In particular, it turns out that all our propositions and the corollary are still valid if the public university provides a high educational quality. 
To summarise, the fact that we consider public, or publicly controlled, universities and assume that the decisions on educational quality and tuition fees take account of the wider fiscal implications strongly drives key conclusions. By contrast, the focus on international competition rather than domestic one seems to be far less important for these conclusions.

\section{Brain Drain and Brain Gain}

Having explored how a changing environment affects educational quality, tuition fees and the allocation of students under various circumstances, we now explore whether, from the perspective of the developing countries, the socio-economic changes analysed in the previous sections yield a brain drain or a brain gain. The findings in the previous sections shed some light on this question and explore novel mechanisms that generate brain drain or brain gain in the context of international competition for students. ${ }^{13}$ In the following, we focus on two scenarios, a rise in the stay rate and an increase in the size of the talent pool.

Stay Rate First of all, an increase in the stay rate $p$ reduces the number of internationally educated graduates who return to ROW, which constitutes a quantitative brain drain. At the same time, an increase in the stay rate alters the competition for international students, with clear-cut implications. Firstly, a larger share of the talent pool is educated in the high-quality country 2 (i.e., $d(1-\hat{a}) / d p>0)$. Secondly, the educational quality in country 2 increases, while the quality in country 1 remains unchanged. Both effects push up the average human capital of graduates who return to ROW, which constitutes a qualitative brain gain. ${ }^{14}$ Overall, ROW suffers from a quantitative brain drain, but it benefits from a qualitative brain gain.

Size of the Talent Pool For a given return rate $(1-p)$, the number of internationally educated graduates in ROW apparently increases with the number of

\footnotetext{
${ }^{13}$ The conclusions in this section are not only valid for public competition, but qualitatively also for the alternative forms of competition discussed in section 4.4.

${ }^{14}$ Haupt et al. (2014) argue that aggregate and per-capita human capital in a developing country increases with the stay rate of international students in a developed host country as long as this stay rate is not too large. In their model, however, there is only one host country, offering a uniform education quality. That is, Haupt et al. (2014) ignore the implications of competition between universities.
} 
students sent abroad, $N$. This increase constitutes a quantitative brain gain. (Moreover, this will certainly lead to a per-capita brain gain if the increase in the number of international students $N$ results from a rising student share of the population in ROW, and not merely from population growth.)

In addition, a rise in the number of international students $N$ alters the competition for ROW-born students. The educational quality $q_{2}$ increases, while the educational quality $q_{1}=0$ remains unchanged. The allocation of students within the host regions stays the same as well. Consequently, the average human capital of the returning graduates increases, implying a qualitative brain gain. Overall, ROW benefits from both a quantitative and qualitative brain gain.

The novelty of these brain gain and brain drain effects is that they are driven by university competition and policy changes in the developed countries. By contrast, the 'standard' economic literature on brain drain and brain gain stresses how migration shapes private incentives to invest in education, as, e.g., in Stark et al. (1998) and Dos Santos and Postel-Vinay (2003). In this sense, our model complements the existing literature on brain drain and brain gain by explicitly considering the host countries' competition for talent from developing countries.

\section{Domestic Students}

In the previous sections, we focused on international students, therefore abstracting from domestic ones. We now include domestic students in our analysis. Even in the presence of domestic students, many university initiatives aim at specifically enhancing the educational quality that international students experience (e.g., through providing additional supervision, tutorials and language courses for international students). If this were solely the case, including domestic students into our model would leave our conclusions unaltered. Beyond these specific investments, however, there are also many investments in 'general' educational quality, i.e., quality that benefits both domestic and foreign students. Let us now investigate whether our previous conclusions remain valid in the presence of domestic students and investments in general educational quality.

To tackle this issue, we extend our basic model by explicitly including domestic students. We assume that each country has a given pool of domestic talent $D$. These students are internationally immobile and are characterised by the same uniform ability distribution as foreign students. We ignore specific educational quality and instead focus on general educational quality only, which is the same for domestic and foreign students in each country and denoted by $q_{i}^{D}$. In line with the practice in many 
countries, we assume that countries can differentiate the tuition fees for domestic and foreign students, with $t_{i}$ still denoting those for international students. ${ }^{15}$ After graduation, immobile domestic students stay in their home country and earn wage $w=\underline{w}+a q_{i}$, as do the foreign graduates who remain in their host country.

Each government acts benevolent towards the domestic pool of talent, and the welfare function of country $i$ now includes the aggregate wage income of its natives net of their variable education costs, denoted by $V_{i}$, in addition to the components of the 'old' objective function (2):

$$
R_{i}^{D}=V_{i}+\tau W_{i}+N_{i}\left[t_{i}-c\left(q_{i}^{D}\right)\right]-F\left(q_{i}^{D}\right)
$$

where $V_{i}=D_{i}\left[\left(\underline{w}+\frac{1}{2} q_{i}^{D}\right)-\alpha q_{i}^{D}\right]$ if all natives attend university. We suppose that this is the case to simplify the presentation without affecting our conclusions qualitatively and show in appendix B under which conditions this situation emerges. Note that neither tuition fees nor taxes paid by natives appear in this welfare function. Since these fees and taxes increase public revenues by the same amount as they reduce aggregate income of natives, they are welfare-neutral. Also, we normalise the wage of a non-graduate to zero.

The threshold value (3) still characterises the demand of the international pool of talent for the two universities. Also, the new term $V_{i}$ of welfare function (18) does not contain the tuition fee $t_{i}$, which is paid by international students, whereas the 'old' welfare terms $\tau W_{i}, N_{i}\left[t_{i}-c\left(q_{i}^{D}\right)\right]$ and $F\left(q_{i}^{D}\right)$ are not affected by the introduction of domestic students other than the fact that all students face the same quality level $q_{i}^{D}$. Consequently, tuition fee competition for the international pool of talent leads to the same results - stated in (8), (9), (10) and (11) — as in the case without domestic students. (Appendix B contains the mathematical details of this section.)

Turning to educational quality competition, we again follow the line of reasoning in section 3. The quality levels are implicitly determined by the conditions

$$
\frac{\partial R_{1}^{D}}{\partial q_{1}^{D}}=\underbrace{D\left(\frac{1}{2}-\alpha\right)}_{\text {income effect }} \underbrace{-\frac{1}{2} \hat{a}^{2} N(p \tau+2 \varrho)}_{\text {competition effect }}-\frac{\partial F}{\partial q_{1}^{D}} \leq 0
$$

which may, or may not, give an interior solution for $q_{1}^{D}$, as discussed shortly, and

$$
\frac{\partial R_{2}^{D}}{\partial q_{2}^{D}}=\underbrace{D\left(\frac{1}{2}-\alpha\right)}_{\text {income effect }} \underbrace{+\frac{1}{2}(1-\hat{a})^{2} N(p \tau+2 \varrho)}_{\text {competition effect }}-\frac{\partial F}{\partial q_{2}^{D}}=0 .
$$

\footnotetext{
${ }^{15}$ For instance, 16 out of 27 OECD member countries examined in OECD (2014: 348) charge higher tuition fees from international students than from domestic ones.
} 
The first term of the two derivatives captures the income gain of the natives from an increase in educational quality. This new effect is positive for $\alpha<1 / 2$, which we assume to be the case. The other terms of the derivatives reflect the impact of educational quality on the contribution of international students to domestic welfare and on the fixed costs of education. They are identical to those in (12) and (13).

Comparing the conditions (19) and (20) with (12) and (13) reveals two differences between the scenarios with and without domestic students. Firstly, educational quality in the low-quality country will be positive if the cohort of domestic students $D$ is large relative to that of international students $N$. On the one hand, a lower quality softens tuition fee competition (competition effect), as explained in section 3. On the other hand, a higher quality increases the future income of domestic students (native income effect). If $D$ is sufficiently large relative to $N$, the latter effect is so strong that an interior solution results, i.e., $\partial R_{1}^{D} / \partial q_{1}^{D}=0$ for $q_{1}>0$. Otherwise, $q_{1}^{D}=0$ holds, as in section 3. Secondly, the educational quality in the high-quality country 2 is higher in the presence of both domestic and international talent than in the absence of either domestic or international students. Both the native income and the competition effect work in the same direction. To put it differently, without foreign talent (i.e., $N=0$ ), both governments would prefer the same positive level of educational quality. Take this level as the benchmark. Then, competition for international students lets governments differentiate educational quality around this benchmark level. Thus, the presence of an international pool of talent has qualitatively the same effect as before, but this effect is softened by the existence of domestic students.

We can now deal with the remaining question of whether, and how, including domestic students affects the way changes in the socio-economic environment shape international competition. Importantly, if $q_{1}^{D}=q_{1}^{*}=0$ resulted, propositions 1 to 3 and corollary 1 would hold true in the extended model without qualification. Thus, we focus instead on the scenario with a positive educational quality $\left(q_{1}^{D}>0\right)$.

Socioeconomic Changes As the threshold level $\hat{a}$, and thus the allocation of international students, is still given by (11), the share of foreign students who study in the high-quality country $(1-\hat{a})$ still increases with the stay rate $p$.

By contrast, the stay rate now has an ambiguous impact on educational quality $q_{1}^{D}$ (assuming that $q_{1}^{D}>0$ ). As the income effect is independent of the stay rate, parameter $p$ affects educational quality only through its influence on the competition effect (see (19)). On the one hand, foreign students become more important for country 1 when the stay rate increases, since it makes them more likely to work in their host country after graduation and pay taxes. On the other hand, they become 
less important for country 1 , since demand shifts from low-quality to high-quality education, reflecting the fact that a higher stay rate increases the income gains from educational quality. If the former direct effect dominates (is dominated by) the latter indirect effect, then country 1 competes more (less) fiercely for the international pool of talent. It then faces a bigger (smaller) incentive to differentiate its educational quality to soften tuition fee competition, and thus reduces (increases) its quality level $q_{1}^{D}$.

The quality level $q_{2}^{D}$ still increases with the stay rate $p$. The income effect changes the quality level $q_{2}^{D}$ but not the impact of $p$ on the educational quality level $q_{2}^{D}$, i.e., $d q_{2}^{D} / d p$ is unaffected and still positive. Importantly, both the direct effect and the indirect effect discussed above work in favour of a higher quality $q_{2}^{D}$ (see (20)).

As the quality $q_{1}^{D}$ might increase with the stay rate $p$, the impact of the stay rate on the quality differential $\Delta q^{D}:=q_{2}^{D}-q_{1}^{D}$ is a priori unclear. The quality differential declines if there is a drastic rise in educational quality $q_{1}^{D}$ relative to quality $q_{2}^{D}$. Such an outcome requires that the positive indirect effect of a higher stay rate on quality $q_{1}^{D}$ is sufficiently strong relative to that on quality $q_{2}^{D}$. This in turn tends to be the case if the cost parameter $\alpha$ is sufficiently large, which particularly curbs the incentives of the high-quality country to invest in its educational quality. For a small cost parameter $\alpha$, by contrast, the quality differential tends to increase with the stay rate and all our conclusions in section 4.1 tend to carry over to this model extension (see appendix B for further details).

Finally, the impact of the stay rate on tuition fees remains ambiguous just like in the case without domestic students. As discussed in detail in section 4.1, a higher stay rate gives rise to opposing effects on the tuition fee differential even if we ignore domestic students, with the educational quality effect and the expected income effect counteracting the direct tax revenue effect. With domestic students, the quality differential might narrow and thus reverse the sign of the educational quality effect, further adding to the already existing ambiguity.

In summary, our new findings are in line with the conclusions in proposition 1 and corollary 1 if the indirect effect of a higher stay rate on quality $q_{1}^{D}$ is not too strong. However, including domestic students into our model adds two important qualifications to the comparative statics results in section 4.1. Firstly, the quality level $q_{1}^{D}$ can now vary with the stay rate and, secondly, a higher stay rate can narrow the quality differential, at least for a large cost parameter $\alpha$. Our extension does not qualitatively affect the other conclusions in proposition 1 and corollary 1.

Considering the effects of a higher income in ROW, we find a similar picture. Our conclusions in proposition 2 carry over to the case with domestic students for 
small variable education costs, but need some qualifications for large ones. Finally, an increase of the pool of international talent $N$ qualitatively brings about (almost) identical results in the scenarios with and without domestic students (see appendix B for further details).

\section{Concluding Remarks}

In this paper, we have analysed the competition between two developed countries for the pool of students from the developing world. In particular, we have been interested in how potential trends in developed and developing countries affect the equilibrium outcome. In this context, a further interesting question is how tax and education policies interact, and how asymmetries in the tax rates affect the equilibrium outcome. If there is a decline in the tax rate in, say, country 2 , this country becomes more attractive to foreign students, and demand for higher education shifts in its favour. As a result, we expect tuition fees to rise in this country, simply reflecting the fact that income tax and tuition fees are imperfect substitutes. The impact of a lower tax rate on educational quality is less clear. On the one hand, the incentive to invest in quality is depressed, as those graduates who continue to stay in country 2 pay lower taxes and are thus less valuable for country 2 . On the other hand, this incentive is reinforced, as students pay higher tuition fees and are thus more valuable. Whether the positive or negative impact on quality dominates should depend on the importance of taxes as revenue source relative to tuition fees, which hinges on the stay rate and the level of taxes and tuition fees.

This short discussion about the interaction between education and tax policies gives rise to the question whether governments could come up with smarter schemes than the ones considered in this paper. In our model, tuition fees can easily be negative. That is, governments might effectively grant scholarships, which are somewhat 'repaid' by future tax payments. However, as all international students pay tuition fees, but only some of them will pay taxes in their host countries, governments might be tempted to erase such scholarships and charge positive tuition fees, but give tax credits to those international students who stay on in their host country after graduation. Such a scheme could be interpreted as a reversed graduate tax.

However, this idea might not be advisable in a more complex environment in which international students are credit constrained and face uncertainty about their future incomes, and in which the education outcome depends on unobservable study effort. In such an environment, tapping into the pool of talent abroad in a competitive way might require to financially support international students and insure 
them, like domestic students, to some extent against income risks, but at the same time deal with the issue of moral hazard. Interestingly, Cigno and Luporini (2009) show that, in this type of environment, a scholarship system financed by a graduate tax can yield a first-best allocation. Their policy suggestion is roughly in line with the potential equilibrium outcome in our basic model, albeit for very different reasons. However, Cigno and Luporini (2009) consider a closed economy in which the government acts as benevolent principal towards its citizens. Thus, it is an open issue whether their conclusions carry over to the case of international students and its additional complications. We leave this question for future research.

Our analysis points to further interesting avenues for future research. For instance, instead of the countries deciding simultaneously, they could make their quality, or market entry, choices sequentially (e.g., by launching international study programmes). Countries would then have an incentive to spend resources to lead the way and obtain a first-mover advantage by choosing the more profitable market segment. Furthermore, it would be worthwhile considering an endogenous immigration policy which determines the stay rates of graduates. Countries could implement some measures to foster social integration and to facilitate the labour market access of graduates (e.g., by promoting permanent residency). More and more OECD countries already make use of this option, and it would be interesting to elaborate the link between immigration policy and the competition for students in more detail.

Acknowledgments: The authors are most thankful to two anonymous reviewers and the journal's editor, Alessandro Cigno, for their excellent help and guidance. In addition, we also thank Michel Beine, Robert Fenge, Marcel Gérard, Julien Jacqmin, Søren Bo Nielsen and Hillel Rapoport for their very helpful comments and suggestions. We also benefited from the very constructive discussions at the IIPF Congress in Capetown, the Global COE Seminar on Public Economics at Hitotsubashi University in Tokyo, the CESifo Workshop on "Financing the Mobility of Higher Education Students and Researchers" in Mons, the AEL Conference on Development Economics and Policy in Berlin, the EEA Annual Meeting in Oslo, the Public Economics Workshop in Bremen, the Conference on "International Labor Mobility and Inequality Across Nations" in Clermont-Ferrand as well as at research seminars at Queen's University in Kingston, TU Dresden, the University of Freiburg, the University of Rostock and the University of Konstanz. Thomas Lange gratefully acknowledges financial support from the German Research Foundation's (DFG) Research Group on Heterogeneous Labor, the Fritz Thyssen Stiftung and the German Academic Exchange Service (DAAD) for a research visit at Queen's University in Kingston. 


\section{Appendix A}

\section{Proof of Lemma 1}

We start by deriving the equilibrium tuition fees (8) and (9). Country 1 chooses $t_{1}$ to maximise net revenues $R_{1}$ according to (6), taking $t_{2}$ and quality levels $\left(q_{1}, q_{2}\right)$ as given. The corresponding first-order condition for given $\Delta q>0$ is, after some rearrangements,

$$
\frac{\partial R_{1}}{\partial t_{1}}=N\left\{\frac{\partial \hat{a}}{\partial t_{1}}\left[p \tau\left(\underline{w}+\hat{a} q_{1}\right)+t_{1}-\alpha q_{1}\right]+\hat{a}\right\}=0,
$$

from which the best-response function $t_{1}=t_{1}^{b r}\left(t_{2} ; q_{1}, q_{2}\right)$ can be derived:

$$
t_{1}=\theta_{1} t_{2}+\frac{p \tau \underline{w}-c\left(q_{1}\right)}{\frac{p \tau q_{1}}{\varrho \Delta q}-2} ; \quad \theta_{1}:=\frac{\frac{p \tau q_{1}}{\varrho \Delta q}-1}{\frac{p \tau q_{1}}{\varrho \Delta q}-2} .
$$

Using (7), we can analogously determine the first-order condition for the tuition fee chosen by country 2 and the best-response function $t_{2}=t_{2}^{b r}\left(t_{1} ; q_{1}, q_{2}\right)$ :

$$
\frac{\partial R_{2}}{\partial t_{2}}=N\left\{-\frac{\partial \hat{a}}{\partial t_{2}}\left[p \tau\left(\underline{w}+\hat{a} q_{2}\right)+t_{2}-\alpha q_{2}\right]+(1-\hat{a})\right\}=0
$$

and

$$
t_{2}=\theta_{2} t_{1}+\frac{\varrho \Delta q+c\left(q_{2}\right)-p \tau \underline{w}}{\frac{p \tau q_{2}}{\varrho \Delta q}+2} ; \quad \theta_{2}:=\frac{\frac{p \tau q_{2}}{\varrho \Delta q}+1}{\frac{\rho \tau q_{2}}{\varrho \Delta q}+2} .
$$

Combining (22) and (24) yields equilibrium tuition fees

$$
\begin{aligned}
& t_{1}^{*}\left(q_{1}, q_{2}\right)=\frac{1}{1-\theta_{1} \theta_{2}}\left[\frac{p \tau \underline{w}-c\left(q_{1}\right)}{\frac{p \tau q_{1}}{\varrho \Delta q}-2}+\theta_{1} \frac{\varrho \Delta q+c\left(q_{2}\right)-p \tau \underline{w}}{\frac{p \tau q_{2}}{\varrho \Delta q}+2}\right], \\
& t_{2}^{*}\left(q_{1}, q_{2}\right)=\frac{1}{1-\theta_{1} \theta_{2}}\left[\theta_{2} \frac{p \tau \underline{w}-c\left(q_{1}\right)}{\frac{p \tau q_{1}}{\varrho \Delta q}-2}+\frac{\varrho \Delta q+c\left(q_{2}\right)-p \tau \underline{w}}{\frac{p \tau q_{2}}{\varrho \Delta q}+2}\right],
\end{aligned}
$$

which finally can be reduced to (8) and (9). These tuition fees are uniquely determined: As the best responses (22) and (24) are continuous functions of the opponent's tuition fee, and as the corresponding best-response curves have slopes of $\theta_{1} \leq 1 / 2$ and $\theta_{2} \in(1 / 2,1)$, these curves intersect only once. The secondorder condition $\partial^{2} R_{2} / \partial t_{2}^{2}=-N\left(\partial \hat{a} / \partial t_{2}\right)\left[p \tau\left(\partial \hat{a} / \partial t_{2}\right) q_{2}+2\right]<0 \Leftrightarrow-p \tau q_{2}-$ $2 \varrho \Delta q<0$ is satisfied for all $\left(q_{1}, q_{2}\right)$; the second-order conditions $\partial^{2} R_{1} / \partial t_{1}^{2}=$ $N\left(\partial \hat{a} / \partial t_{1}\right)\left[p \tau\left(\partial \hat{a} / \partial t_{1}\right) q_{1}+2\right]<0$ is fulfilled for $p \tau q_{1}-2 \varrho \Delta q<0 \Leftrightarrow q_{2}>$ $[(p \tau / 2 \rho)+1] q_{1}$. Under the latter condition, both second-order conditions are satisfied. Then, the second-stage equilibrium is unique and given by the tuition fees (8) and (9) and the allocation of students (11). In particular, this is the case for the 
quality levels $q_{2}^{*}>q_{1}^{*}=0$ that follow from conditions (12) and (13) and for quality levels in the larger neighbourhood of $q_{2}^{*}$ and $q_{1}^{*}$. (We assume $p \tau+2 \varrho-\alpha>0$ to guarantee $0<\hat{a}^{*}<1$ and to exclude boundary solutions, which were not characterised by (8) and (9) for $q_{2}^{*}>q_{1}^{*}=0$. This assumption underlies our arguments above. Further details are provided on request.)

As the second-order condition $d^{2} R_{2} / d q_{2}^{2}=-\partial^{2} F / \partial q_{2}^{2}<0$ is fulfilled (see (13)), the solution $\left(t_{1}^{*}\left(q_{1}^{*}, q_{2}^{*}\right), t_{2}^{*}\left(q_{1}^{*}, q_{2}^{*}\right), q_{1}^{*}, q_{2}^{*}, \hat{a}^{*}\right)$ constitutes a local equilibrium if we can additionally prove that both governments achieve positive net benefits, i.e., $R_{i}>0$ for $q_{2}^{*}>q_{1}^{*}=0$. First, we show that net variable rents $r_{i}\left(q_{1}, q_{2}\right)=\tau W_{i}+N_{i}\left[t_{i}-\right.$ $\left.c\left(q_{i}\right)\right]>0$ are strictly positive. Inserting equilibrium values $t_{1}^{*}, t_{2}^{*}$ and $\hat{a}^{*}$, which are defined by (8), (9) and (11), in the net variable rents (see the corresponding terms in (6) and (7)) yields, after some rearrangements,

$$
\begin{aligned}
& r_{1}\left(q_{1}, q_{2}\right)=N\left(\frac{\alpha+\varrho}{p \tau+3 \varrho}\right)\left(\frac{\rho\left(2 \varrho \Delta q-p \tau q_{1}\right)+\alpha\left(4 \varrho \Delta q-p \tau q_{1}\right)}{2(p \tau+3 \rho)}\right), \\
& r_{2}\left(q_{1}, q_{2}\right)=N\left(\frac{p \tau+2 \varrho-\alpha}{p \tau+3 \varrho}\right)\left(\frac{(p \tau+2 \varrho-\alpha)\left(2 \varrho \Delta q+p \tau q_{2}\right)}{2(p \tau+3 \varrho)}\right),
\end{aligned}
$$

which not only shows that net variable rents $r_{1}$ and $r_{2}$ decline with quality $q_{1}$, but more importantly that

$$
\begin{aligned}
& r_{1}\left(q_{1}, q_{2}\right)>0 \quad \text { if } \quad p \tau q_{1}-2 \varrho \Delta q<0, \\
& r_{2}\left(q_{1}, q_{2}\right)>0 \quad \text { if } \quad\left(\frac{p \tau}{2} q_{2}+\varrho \Delta q\right)(p \tau+2 \varrho-\alpha)>0 .
\end{aligned}
$$

Thus, net variable rent $r_{1}\left(q_{1}, q_{2}\right)$ is strictly positive if the second-order condition $\partial^{2} R_{1} / \partial t_{1}^{2}<0 \Leftrightarrow p \tau q_{1}-2 \varrho \Delta q<0$ is satisfied, which is the case for $q_{2}^{*}>q_{1}^{*}=0$. Similarly, net variable rent $r_{2}\left(q_{1}, q_{2}\right)$ is strictly positive, as we assume $p \tau+2 \varrho-\alpha>0$ (which guarantees that $\hat{a}^{*}<1$ ). With $q_{2}^{*}>q_{1}^{*}=0$, country 1 generates a strictly positive benefit $R_{1}>0$ (see (6)) because $F(0)=0$ and $r_{1}\left(q_{1}^{*}, q_{2}^{*}\right)>0$.

Country 2 also generates a strictly positive rent $R_{2}$, as $\lim _{q_{2} \rightarrow 0} R_{2}\left(0, q_{2}\right)=0$ implies $q_{2}^{*}=\arg \max R_{2}\left(q_{2}\right)>0 \Leftrightarrow R_{2}\left(q_{2}^{*}\right)>0$.

The equilibrium allocation of students is $\hat{a}^{*}$. From (3) follows that all individuals with ability $a \geq \hat{a}^{*}$ study in the high-quality country 2 , while all students with $a<\hat{a}^{*}$ study in country 1 .

\section{Proof of Non-existence of Symmetric Equilibrium}

To show that a symmetric solution cannot exist, we first analyse tuition fee competition, assuming that the two countries chose identical educational qualities $q_{1}=q_{2}=: q$ in the first stage. Assume that students who are indifferent between 
the two countries study in each of the two countries with probability 0.5. For undifferentiated quality levels, the variable net rent then amounts to

$$
\left.r_{i}\right|_{\Delta q=0}=\left\{\begin{array}{lll}
\tau W+N\left(t_{i}-c(q)\right) & \text { if } \quad t_{i}<t_{j}, \\
\frac{1}{2}\left[\tau W+N\left(t_{i}-c(q)\right)\right] & \text { if } \quad t_{i}=t_{j}, \\
0 & \text { if } \quad t_{i}>t_{j},
\end{array}\right.
$$

where $W=p N \int_{0}^{1}(\underline{w}+a q) d a=p N(\underline{w}+q / 2)$. The fixed costs of providing quality are already sunk and therefore irrelevant for tuition fee competition. Countries have an incentive to undercut their competitor in order to attract all foreign students as long as $r_{i}$ is positive, thereby engaging in a race-to-the-bottom leading to tuition fees $t_{1}=t_{2}=\alpha q-p \tau(\underline{w}+q / 2)$ and $r_{i}=0$.

This result of the second stage affects, in turn, the overall rent $R_{i}$ after taking quality competition into account. If the variable net rent in (6) and (7) is zero, only the fixed costs remain, i.e., $R_{i}=-F(q), i=1,2$. Then educational qualities $q_{1}=q_{2}>0$ cannot constitute an equilibrium. One country could unilaterally deviate and choose, for instance, an educational quality of zero, thereby reducing fixed costs $F(q)$ to zero, while the ensuing tuition fee competition would lead to positive net variable revenues according to (27). Thus, net benefits of this country would rise from $-F(q)$ to a positive value.

Next, the solution $q_{1}=q_{2}=0$, implying $R_{1}=R_{2}=0$, cannot be an equilibrium either. The reason is that one country, say country 2 , can then gain from unilaterally raising its quality to $q_{2}^{*}$ and realising positive net revenues $R_{2}>0$, as explored in the proof of lemma 1 .

\section{Proof of Proposition 1}

First of all, note that

$$
\frac{\partial \varrho(p)}{\partial p}=(1-\tau)-\left(1-\tau_{R O W}\right) \gamma \geq 0
$$

can be signed unambiguously by Assumption 1. This finding can be used to get, from (1) and (11),

$$
\frac{d \hat{a}^{*}}{d p}=-\frac{\tau\left[\left(1-\tau_{\mathrm{ROW}}\right) \gamma+\alpha\right]+3 \alpha \frac{\partial \varrho}{\partial p}}{(p \tau+3 \varrho)^{2}}<0,
$$

and thus $\partial\left(1-\hat{a}^{*}\right) / \partial p>0$. This proves part (iii) of proposition 1 .

Now, part (i) follows from

$$
\frac{d \Delta q^{*}}{d p} \gtreqless 0 \quad \stackrel{\left(q_{1}^{*}=0\right)}{\Leftrightarrow} \quad \frac{d q_{2}^{*}}{d p}=-\frac{d^{2} R_{2} /\left(d q_{2} d p\right)}{d^{2} R_{2} / d q_{2}^{2}} \gtreqless 0
$$




$$
\stackrel{(13)}{\Leftrightarrow} \quad \frac{d^{2} R_{2}}{d q_{2} d p}=\frac{d\left[\frac{N}{2}(p \tau+2 \varrho)\left(1-\hat{a}^{*}\right)^{2}\right]}{d p} \gtreqless 0 .
$$

Further, we can show that

$$
\frac{d^{2} R_{2}}{d q_{2} d p}=\frac{N\left(1-\hat{a}^{*}\right)}{2}\left[\left(\tau+2 \frac{\partial \varrho}{\partial p}\right)\left(1-\hat{a}^{*}\right)-2(p \tau+2 \varrho) \frac{\partial \hat{a}^{*}}{\partial p}\right]>0,
$$

where the last inequality results from $\partial \varrho / \partial p \geq 0$ (see (32)), $\partial \hat{a}^{*} / \partial p<0$ (see (33)) and $1-\hat{a}^{*}>0$. That means that from (36) follows that the sign of $d \Delta q^{*} / d p$ is positive. Thus, $d q_{2}^{*} / d p>0$ also results, as $q_{1}^{*}=0$ irrespective of $p$.

Considering the tuition fee differential (10), we get

$$
\begin{aligned}
\frac{d \Delta t^{*}}{d p} & =\Omega \frac{d \Delta q^{*}}{d p}+\Delta q^{*}\left\{\frac{d \Omega}{d p}+\frac{\partial \Omega}{\partial \varrho} \frac{\partial \varrho}{\partial p}\right\} \\
& =\Omega \frac{\Delta q^{*}}{p}\{\underbrace{\frac{d \Delta q^{*}}{d p} \frac{p}{\Delta q^{*}}}_{:=\varepsilon_{\Delta q, p}>0}+\underbrace{\frac{\partial \Omega}{\partial p} \frac{p}{\Omega}}_{:=\varepsilon_{\Omega, p}<0}+\underbrace{\frac{\partial \Omega}{\partial \varrho} \frac{\varrho}{\Omega}}_{:=\varepsilon_{\Omega, \varrho}>0} \cdot \underbrace{\frac{\partial \varrho}{\partial p} \frac{p}{\varrho}}_{:=\varepsilon_{\varrho, p} \geq 0}\},
\end{aligned}
$$

where $\varepsilon_{\Delta q, p}:=(d \Delta q / d p)(p / \Delta q)>0, \varepsilon_{\Omega, p}:=(\partial \Omega / \partial p)(p / \Omega)<0$, and $\varepsilon_{\varrho, p}:=$ $(\partial \varrho / \partial p)(p / \varrho) \geq 0$ follow directly from (34)-(36), (10), and (32). Furthermore, $\varepsilon_{\Omega, \varrho}=(\partial \Omega / \partial \varrho)(\varrho / \Omega)>0$ results from

$$
\frac{\partial \Omega}{\partial \varrho}=\frac{p \tau(\alpha+2 \varrho)+3 \varrho^{2}}{(p \tau+3 \varrho)^{2}}>0
$$

The derivative (38) directly implies (14), which is stated in part (ii) of proposition 1. Furthermore, for $q_{1}=0$, we get $t_{2}^{*}=2 t_{1}^{*}+p \tau \underline{w}$ and $t_{1}^{*}=(1 / 2)\left(t_{2}^{*}-p \tau \underline{w}\right.$ ) (see (8) and (9)), leading to $\Delta t^{*}=t_{2}^{*}-t_{1}^{*}=t_{1}^{*}+p \tau \underline{w}=(1 / 2)\left(t_{2}^{*}+p \tau \underline{w}\right)$ and thus

$d \Delta t^{*} / d p=d t_{1}^{*} / d p+\tau \underline{w}=(1 / 2)\left(d t_{2}^{*} / d p+\tau \underline{w}\right)$. Then, $d \Delta t^{*} / d p<0$ implies $d t_{1}^{*} / d p<0$ and $d t_{2}^{*} / d p<0$. However, $d t_{1}^{*} / d p>0$ or $d t_{2}^{*} / d p>0$ is possible if $d \Delta t^{*} / d p>0$. To summarise, the impact of the stay rate $p$ on the tuition fee differential and the tuition fees $t_{1}^{P}$ and $t_{2}^{P}$ is ambiguous.

\section{Proof of Proposition 2}

Part (i) of proposition 2 follows from

$$
\begin{aligned}
& \frac{d \Delta q^{*}}{d \gamma} \gtreqless 0 \quad \stackrel{\left(q_{1}^{*}=0\right)}{\Leftrightarrow} \quad \frac{d q_{2}^{*}}{d \gamma}=-\frac{d^{2} R_{2} /(d q d \gamma)}{d^{2} R_{2} / d q_{2}^{2}} \gtreqless 0 \\
& \stackrel{(13)}{\Leftrightarrow} \quad \frac{d^{2} R_{2}}{d q d \gamma}=\frac{d\left[\frac{N}{2}(p \tau+2 \varrho)\left(1-\hat{a}^{*}\right)^{2}\right]}{d \varrho} \frac{d \varrho}{d \gamma} \gtreqless 0
\end{aligned}
$$


and, using (11) and the fact that $d \varrho / d \gamma=(1-p)\left(1-\tau_{R O W}\right)>0$ (see $\left.(1)\right)$,

$$
\frac{d^{2} R_{2}}{d q d \gamma}>0 \Leftrightarrow 3 \varrho p \tau+6 \varrho^{2}+2 \alpha p \tau+3 \alpha \varrho>0,
$$

where the last inequality always holds. Thus, $d \Delta q^{*} / d p>0$, implying $d q_{2}^{*} / d p>0$ because $q_{1}^{*}=0$ irrespective of $p$.

Using (10), part (ii) of proposition 2 follows from

$$
\frac{d \Delta t^{*}}{d \gamma}=\frac{\partial \Delta t^{*}}{\partial \varrho} \cdot \frac{\partial \varrho}{\partial \gamma}+\frac{\partial \Delta t^{*}}{\partial \Delta q^{*}} \cdot \frac{d \Delta q^{*}}{d \gamma}>0
$$

where $\partial \Delta t^{*} / \partial \Delta q^{*}=\Omega(p, \varrho)>0$ (see (10)), $d \Delta q^{*} / d \gamma>0$ (see (40)-(42)), $\partial \varrho / \partial \gamma=$ $(1-p)\left(1-\tau_{R O W}\right)>0($ see $(1))$, and

$$
\frac{\partial \Delta t^{*}}{\partial \varrho}=\frac{p \tau(\alpha+2 \varrho)+3 \varrho^{2}}{(p \tau+3 \varrho)^{2}} \Delta q^{*}>0
$$

(see (10) and (39)). Moreover, $d \Delta t^{*} / d \gamma>0$ implies $d t_{1}^{*} / d \gamma>0$ and $d t_{2}^{*} / d \gamma>0$, since $\Delta t^{*}=t_{2}^{*}-t_{1}^{*}=t_{1}^{*}+p \tau \underline{w}=(1 / 2)\left(t_{2}^{*}+p \tau \underline{w}\right.$ ) (see proof of proposition 1) and thus $d \Delta t^{*} / d \gamma=d t_{1}^{*} / d \gamma=(1 / 2) d t_{2}^{*} / d \gamma$.

Also, using (1) and (11) yields

$$
\frac{d\left(1-\hat{a}^{*}\right)}{d \gamma} \gtreqless 0 \quad \Leftrightarrow \quad-\frac{\partial \hat{a}^{*}}{d \varrho} \frac{\partial \varrho}{\partial \gamma} \gtreqless 0 \quad \Leftrightarrow \quad 3 \alpha-p \tau \gtreqless 0,
$$

which proves part (iii) of proposition 2 .

\section{Proof Proposition 3}

Applying comparative statics again yields

$$
\frac{\partial \Delta q^{*}}{\partial N} \gtreqless 0 \quad \stackrel{\left(q_{1}^{*}=0\right)}{\Leftrightarrow} \quad \frac{\partial q_{2}^{*}}{\partial N} \gtreqless 0 \quad \stackrel{(13)}{\Leftrightarrow} \quad \frac{\partial}{\partial N}\left[\frac{N}{2}(p \tau+2 \varrho)\left(1-\hat{a}^{*}\right)^{2}\right] \gtreqless 0,
$$

with

$$
\frac{\partial}{\partial N}\left[\frac{N}{2}(p \tau+2 \varrho)\left(1-\hat{a}^{*}\right)^{2}\right]=\frac{1}{2}(p \tau+2 \varrho)\left(1-\hat{a}^{*}\right)^{2}>0 .
$$

Thus, $d \Delta q^{*} / d N>0$ and, as $q_{1}^{*}=0$ irrespective of $p, d q_{2}^{*} / d N>0$, as stated in part (i) of proposition 3 .

Part (ii) follows from

$$
\frac{d \Delta t^{*}}{d N}=\frac{\partial \Delta t^{*}}{\partial \Delta q^{*}} \cdot \frac{\partial \Delta q^{*}}{\partial N}>0
$$

where $\partial \Delta t^{*} / \partial \Delta q^{*}=\Omega(p, \varrho)>0($ see $(10))$ and $\partial \Delta q^{*} / \partial N>0$ (see (46) and (47)). In line with our previous reasoning, $d \Delta t^{*} / d N>0$ implies $d t_{i}^{*} / d N>0$, since $\Delta t^{*}=$ $t_{2}^{*}-t_{1}^{*}=t_{1}^{*}+p \tau \underline{w}=(1 / 2)\left(t_{2}^{*}+p \tau \underline{w}\right)$ and thus $d \Delta t^{*} / d N=d t_{1}^{*} / d N=(1 / 2) d t_{2}^{*} / d N$.

Part (iii) follows directly from (11), as $\hat{a}^{*}$ is independent of $N$. 


\section{Appendix B}

\section{B.1 Competition between Private Universities (Section 4.4)}

Let us start by analysing the competition between two private universities for the international pool of talent. As indicated in the paper, we explore a slightly more general model in this appendix than the one informally discussed in section 4.4 of the paper. As in this section of the paper, the private universities are not interested in how their decisions affect future tax payments, but in contrast to this section, they now receive a prestige benefit from well-educated alumni. This additional benefit enters their objective function

$$
R_{i}^{P}=\lambda A_{i}+N_{i}\left[t_{i}-c\left(q_{i}\right)\right]-F\left(q_{i}\right)
$$

where $\lambda \geq 0$ captures the weight assigned to the prestige benefit, $A_{i}$ stands for the aggregate human capital generated by university $i$, and the superscript $P$ indicates the scenario with private competition. In the paper, we discuss the special case of $\lambda=0$. As we will see, considering the more general case of $\lambda \geq 0$ does not alter the results informally discussed in the paper.

\section{Quality and Tuition Fee Competition Revisited 1}

The threshold value (3) still characterises the demand of the international students for the two universities. Thus, the two universities generate human capital $A_{1}=$ $N \int_{0}^{\hat{a}} a q_{1} d a=\frac{1}{2} \hat{a}^{2} q_{1} N$ and $A_{2}=N \int_{\hat{a}}^{1} a q_{2} d a=\frac{1}{2}\left(1-\hat{a}^{2}\right) q_{2} N$, respectively. Using these terms to rearrange objective function (49) yields

$$
\begin{gathered}
R_{1}^{P}=\hat{a} N\left\{\frac{1}{2} \lambda \hat{a} q_{1}+t_{1}-c\left(q_{1}\right)\right\}-F\left(q_{1}\right), \\
R_{2}^{P}=(1-\hat{a}) N\left\{\frac{1}{2} \lambda(1+\hat{a}) q_{2}+t_{2}-c\left(q_{2}\right)\right\}-F\left(q_{2}\right) .
\end{gathered}
$$

The differences between these objective functions and their counterparts (6) and (7) are that the tax revenue term $\tau p$ is replaced with the prestige term $\lambda$, and that the wage component $\underline{w}$ is not included (as future tax revenues are now not taken into account). These differences will become important when we discuss the impact of changes in the socio-economic environment on education policy and student allocation.

First, we analyse the tuition fee competition in the second stage under the new circumstances. The universities choose their tuition fees $t_{1}$ and $t_{2}$, respectively, to maximise their objectives $R_{1}^{P}$ and $R_{2}^{P}$, taking the quality levels $\left(q_{1}, q_{2}\right)$ and their 
rival's tuition fee as given. Using threshold value (3) and differentiating objective functions (50) and (51), we get

$$
\frac{d R_{1}^{P}}{d t_{1}}=N\left[\frac{d \hat{a}}{d t_{1}}\left(\lambda \hat{a} q_{1}+t_{1}-\alpha q_{1}\right)+\hat{a}\right]=0 \Leftrightarrow t_{1}^{P}=\hat{a} \varrho\left(q_{2}-q_{1}\right)-\lambda \hat{a} q_{1}+\alpha q_{1}
$$

and

$$
\begin{aligned}
\frac{d R_{2}^{P}}{d t_{2}} & =N\left[-\frac{d \hat{a}}{d t_{2}}\left(\lambda \hat{a} q_{2}+t_{2}-\alpha q_{2}\right)+(1-\hat{a})\right]=0 \\
& \Leftrightarrow t_{2}^{P}=(1-\hat{a}) \varrho\left(q_{2}-q_{1}\right)-\lambda \hat{a} q_{2}+\alpha q_{2} .
\end{aligned}
$$

Then, using equations (52) and (53) gives us the threshold level

$$
\hat{a}^{P}=\frac{\alpha+\varrho}{\lambda+3 \varrho}
$$

and the tuition fee differential

$$
\Delta t^{P}(\Delta q):=t_{2}^{P}-t_{1}^{P}=\Omega^{P}(p, \rho) \Delta q, \quad \text { where } \quad \Omega^{P}(p, \rho)=\frac{\varrho(\alpha+\varrho)}{\lambda+3 \varrho} .
$$

In the following, we assume $\alpha<\lambda+2 \rho$ to guarantee $\hat{a}^{P}<1$. The corresponding tuition fees are given by

$$
\begin{aligned}
& t_{1}^{P}\left(q_{1}, q_{2}\right)=\frac{\varrho\left[\varrho \Delta q-\lambda q_{1}+\alpha\left(q_{2}+2 q_{1}\right)\right]}{\lambda+3 \varrho}, \\
& t_{2}^{P}\left(q_{1}, q_{2}\right)=\frac{\varrho\left[2 \varrho \Delta q-\lambda q_{1}+\alpha\left(q_{1}+2 q_{2}\right)\right]}{\lambda+3 \varrho} .
\end{aligned}
$$

Second, we explore quality competition in the first stage. Using the solutions (54), (56) and (57), we get the derivative

$$
\frac{d R_{1}}{d q_{1}}=\hat{a}^{P} N\left[\frac{\lambda}{2} \hat{a}^{P}+\frac{\partial t_{1}^{P}}{\partial q_{1}}-\alpha\right]-\frac{\partial F}{\partial q_{1}}=-\frac{N}{2}(\lambda+2 \varrho)\left(\hat{a}^{P}\right)^{2}-\frac{\partial F}{\partial q_{1}}<0,
$$

which implies $q_{1}^{P}=0$, and the first-order condition

$$
\begin{aligned}
\frac{d R_{2}}{d q_{2}} & =\left(1-\hat{a}^{P}\right) N\left[\frac{\lambda}{2}\left(1+\hat{a}^{P}\right)+\frac{\partial t_{2}^{P}}{\partial q_{2}}-\alpha\right]-\frac{\partial F}{\partial q_{1}} \\
& =\frac{N}{2}(\lambda+2 \varrho)\left(1-\hat{a}^{P}\right)^{2}-\frac{\partial F}{\partial q_{2}}=0
\end{aligned}
$$

which implicitly determines the optimal quality level $q_{2}^{P}>0$.

In line with the solution in the case of the basic model, the threshold level (54), the tuition fees (56) and (57), the first-order condition (59) and the quality level $q_{1}^{P}=0$ jointly characterise a local equilibrium with $q_{2}^{P}>q_{1}^{P}=0$ and $t_{2}^{P}>t_{1}^{P}$. In 
this local equilibrium, the high-quality university attracts the brightest students, i.e., those with $a \in\left[\hat{a}^{P}, 1\right]$, whereas the low-quality university takes the other students (see lemma 1 in the paper for comparison). Note that when competition is between private universities, the outcome is independent of whether the universities are located in two different countries or the same country.

Comparing the corresponding local equilibria in the cases of private and public competition reveals similarities and differences. Firstly, the low-quality university sets its quality level equal to zero in both cases for the very same reason. It differentiates its quality level as much as possible from the quality level of its competitor to soften tuition fee competition.

Secondly, the high educational quality is higher (lower) under private competition than under public competition if and only if the prestige parameter $\lambda$ is greater (smaller) than the average tax term $p \tau$. Also, a higher (lower) quality $q_{2}$ goes hand in hand with a higher (lower) share of students who are enrolled at the high-quality university. These conclusions follow from comparing the first-order conditions (59) and (13) and the threshold levels (54) and (11), which reveals that $q_{2}^{P} \gtreqless q_{2}^{*} \Leftrightarrow \lambda \gtreqless$ $p \tau \Leftrightarrow 1-a_{2}^{P} \gtreqless 1-a_{2}^{*}$.

Thirdly, tuition fees and the tuition fee differential can be greater or smaller under private competition. However, if the high educational quality is the same under private and public competition (i.e. if $\lambda=p \tau$ ), then the tuition fees of both universities are higher under private competition than under public competition while the tuition fee differential is the same under the two forms of competition. This conclusion follows from comparing tuition fees (8), (9), (56) and (57) and tuition fee differentials (10) and (55), which reveals that, for $\lambda=p \tau, t_{i}^{P}=t_{i}^{*}+p \tau \underline{w}>t_{i}^{*}$ and thus $\Delta t_{i}^{P}=\Delta t_{i}^{*}$.

In the special case of $\lambda=0$, which is discussed in the paper, the universities assign no weight to the prestige benefit and consider international students only as an additional source of net revenues. Then, as private universities ignore the fiscal externalities of international students, the education quality $q_{2}$ and the quality differential $\Delta q$ are definitely lower under private competition than under public competition. The tuition fees of the two universities and the tuition fee differential might be higher or lower. In any case, fewer students are then enrolled at the highquality university. 


\section{Competition in a Changing Environment Revisited 1}

First, let us analyse how a marginal change in the stay rate $p$ affects the local equilibrium. Differentiating equilibrium threshold (54) gives

$$
\frac{d \hat{a}^{P}}{d p}=\frac{\partial \hat{a}}{\partial \varrho} \frac{\partial \varrho}{\partial p}=\frac{\lambda-3 \alpha}{(\lambda+3 \varrho)^{2}} \underbrace{\frac{\partial \varrho}{\partial p}}_{\geq 0} \gtreqless 0 \quad \Leftrightarrow \quad \lambda-3 \alpha \gtreqless 0 \text { if } \frac{\partial \varrho}{\partial p}>0
$$

and thus $\partial\left(1-\hat{a}^{P}\right) / \partial p \gtreqless 0 \Leftrightarrow 3 \alpha-\lambda \gtreqless 0$ if $\partial \varrho / \partial p>0$, where $d \varrho / d p \geq 0$ follows from (32). In contrast to the case of $\lambda=0$, which is discussed in the paper, and in contrast to the case of public competition, the share $\left(1-\hat{a}^{P}\right)$ of foreign students who study at the high-quality university can even decline with the stay rate $p$ if the prestige parameter $\lambda$ is sufficiently large.

Next, we show that quality $q_{2}^{P}$ and the quality differential $\Delta q^{P}$ increase with the stay rate $p$. This conclusion follows from

$$
\begin{aligned}
\frac{d \Delta q^{P}}{d p} \geq 0 \stackrel{\left(q_{1}^{P}=0\right)}{\Leftrightarrow} \quad \frac{d q_{2}^{P}}{d p}=-\frac{d^{2} R_{2}^{P} / d q_{2}^{P} d p}{d^{2} R_{2}^{2} / d\left(q_{2}^{P}\right)^{2}} \geq 0 \Leftrightarrow \\
\frac{d^{2} R_{2}^{P}}{d q_{2}^{P} d p}=\left(1-\hat{a}^{P}\right) N\left[\left(1-\hat{a}^{P}\right) \frac{\partial \varrho}{\partial p}-(\lambda+2 \varrho) \frac{d \hat{a}^{P}}{d p}\right] \\
=\left(1-\hat{a}^{P}\right) N\left[\frac{3 \rho(\lambda+2 \rho+\alpha)+2 \alpha \rho}{(\lambda+3 \rho)^{2}}\right] \frac{\partial \varrho}{\partial p} \geq 0,
\end{aligned}
$$

where we used (59), (60) and $\partial \varrho / \partial p \geq 0$ (see (32)). For $\tau=\tau_{R O W}$ and $\gamma=1$, $\partial \varrho / \partial p=0$ results and the quality $q_{2}$ does not alter in response to changes in the stay rate $q_{2}$. Obviously, quality $q_{1}^{P}=0$ is unaffected by any socioeconomic changes.

Differentiating the tuition fee differential (55) with respect to the stay rate yields

$$
\begin{aligned}
\frac{d \Delta t^{P}}{d p} & =\Omega^{P} \frac{d q_{2}^{P}}{d p}+\Delta q^{P} \frac{\partial \Omega^{P}}{\partial \varrho} \frac{\partial \varrho}{\partial p} \\
& =\Omega^{P} \frac{q_{2}^{P}}{p}\{\underbrace{\frac{d \Delta q^{P}}{d p} \frac{p}{\Delta q^{P}}}_{=: \varepsilon_{\Delta q, p} \geq 0}+\underbrace{\frac{\partial \Omega^{P}}{\partial \varrho} \frac{\varrho}{\Omega^{P}}}_{=: \varepsilon_{\Omega^{P}, p}>0} \cdot \underbrace{\frac{\partial \varrho}{\partial p} \frac{p}{\varrho}}_{=: \varepsilon_{\varrho, p} \geq 0}\} \geq 0 .
\end{aligned}
$$

where the last inequality follows from $d q_{2}^{P} / d p \geq 0$ (see (61)), $\partial \varrho / \partial p \geq 0$ (see (32)) and

$$
\frac{\partial \Omega^{P}}{\partial \varrho}=\frac{\lambda(\alpha+2 \varrho)+3 \varrho^{2}}{(\lambda+3 \varrho)^{2}}>0 .
$$

Furthermore, for $q_{1}^{P}=0$, we get $t_{2}^{P}=2 t_{1}^{P}$, leading to $\Delta t^{P}=t_{2}^{P}-t_{1}^{P}=t_{1}^{P}$. Then, $d t_{1}^{P} / d p=d \Delta t^{P} / d p \geq 0$ and, as $t_{2}^{P}=2 t_{1}^{P}, d t_{2}^{P} / d p=2 d \Delta t^{P} / d p \geq 0$. That is, the tuition fees $t_{1}^{P}$ and $t_{2}^{P}$ and the tuition fee differential increase with the stay rate $p$. 
Second, we analyse how a marginal rise in the income in the rest of the world, i.e., a marginal rise in $\gamma$, affects the local equilibrium. A marginal increase in the ROW parameter $\gamma$ has an ambiguous effect on the share $\left(1-\hat{a}^{P}\right)$ of students who study at the high-quality university:

$$
\frac{d \hat{a}^{P}}{d \gamma}=\frac{\partial \hat{a}^{P}}{\partial \varrho} \frac{\partial \varrho}{\partial \gamma}=\frac{\lambda-3 \alpha}{(\lambda+3 \varrho)^{2}}(1-p)\left(1-\tau_{R O W}\right) \gtreqless 0 \quad \Leftrightarrow \quad \lambda-3 \alpha \gtreqless 0
$$

and thus $\partial\left(1-\hat{a}^{P}\right) / \partial p \gtreqless 0 \Leftrightarrow 3 \alpha-\lambda \gtreqless 0$, where we used $\partial \varrho / \partial \gamma=(1-p)\left(1-\tau_{R O W}\right)>$ 0 (see (1)). However, in the special case of $\lambda=0$, a higher income in ROW leads to a (weakly) higher share of students who are enrolled at the high-quality university.

Next, following the same line of reasoning as before, we can show that quality $q_{2}$ and the quality differential $\Delta q^{P}$ increase with the ROW income parameter $\gamma$. This conclusion follows from

$$
\begin{aligned}
\frac{d \Delta q^{P}}{d \gamma}>0 & \stackrel{\left(q_{1}^{P}=0\right)}{\Leftrightarrow} \quad \frac{d q_{2}^{P}}{d \gamma}=-\frac{d^{2} R_{2}^{P} / d q_{2}^{P} d \gamma}{d^{2} R_{2}^{2} / d\left(q_{2}^{P}\right)^{2}}>0 \Leftrightarrow \\
\frac{d^{2} R_{2}^{P}}{d q_{2}^{P} d \gamma} & =\left(1-\hat{a}^{P}\right) N\left[\left(1-\hat{a}^{P}\right) \frac{\partial \varrho}{\partial \gamma}-(\lambda+2 \varrho) \frac{d \hat{a}^{P}}{d \gamma}\right] \\
& =\left(1-\hat{a}^{P}\right) N\left[\frac{3 \rho(\lambda+2 \rho+\alpha)+2 \alpha \rho}{(\lambda+3 \rho)^{2}}\right] \frac{\partial \varrho}{\partial \gamma}>0,
\end{aligned}
$$

where we used (59), (65) and again $\partial \varrho / \partial \gamma=(1-p)\left(1-\tau_{R O W}\right)>0($ see $(1))$.

Furthermore, the tuition fee differential $\Delta t^{P}$ increases with the ROW income parameter $\gamma$, since

$$
\frac{d \Delta t^{P}}{d \gamma}=\Omega^{P} \frac{d q_{2}^{P}}{d \gamma}+q_{2}^{P} \frac{\partial \Omega^{P}}{\partial \varrho} \frac{\partial \varrho}{\partial \gamma}>0
$$

where the last inequality follows from $d q_{2}^{P} / d \gamma>0$ (see (66)), $\partial \varrho / \partial \gamma=(1-p)(1-$ $\left.\tau_{R O W}\right)>0($ see $(1))$ and $\partial \Omega^{P} / \partial \varrho>0$ (see (64)). Using again $t_{2}^{P}=2 t_{1}^{P}$ and thus $\Delta t^{P}=t_{1}^{P}$, we can conclude that $d t_{2}^{P} / d \gamma=2 d t_{1}^{P} / d \gamma=2 d \Delta t^{P} / d \gamma>0$. That is, the tuition fees $t_{1}^{P}$ and $t_{2}^{P}$ also increase with the ROW income parameter $\gamma$.

Finally, we analyse how an increase in the size of the international pool of talent affects the local equilibrium. Inspection of (59) reveals that

$$
\frac{d q_{2}^{P}}{d N}>0 \Leftrightarrow \frac{d^{2} R_{2}^{P}}{d q_{2}^{P} d N}=\frac{\partial}{\partial N}\left[\frac{N}{2}(\lambda+2 \varrho)\left(1-\hat{a}^{P}\right)^{2}\right]=\frac{1}{2}(\lambda+2 \varrho)\left(1-\hat{a}^{P}\right)^{2}>0,
$$

where the last inequality is obviously satisfied.

Furthermore, $d q_{2}^{P} / d N>0$ (see (69)), $\partial \Delta t^{P} / \partial \Delta q^{P}=\Omega^{P}>0$ (see (55)) and $d \Omega^{P} / d N=0($ see again $(55))$ imply that $d \Delta t^{P} / d N=\left(\partial \Delta t^{P} / \partial \Delta q^{P}\right)\left(d \Delta q^{P} / d N\right)=$ 
$\Omega^{P}\left(d q_{2}^{P} / d N\right)>0$. Using again $t_{2}^{P}=2 t_{1}^{P}$ and thus $\Delta t^{P}=t_{1}^{P}$, we get $d t_{2}^{P} / d N=$ $2 d t_{1}^{P} / d N=2 d \Delta t^{P} / d N>0$. Thus, the tuition fees $t_{1}^{P}$ and $t_{2}^{P}$, the tuition fee differential $\Delta t^{P}$, the education quality $q_{2}^{P}$ and the quality differential $\Delta q^{P}$ all increase with the cohort size parameter $N$. As (54) is independent of $N$, the allocation of students, i.e., $\hat{a}^{P}$, is unaffected by changes in the size of the pool of talent.

\section{B.2 Domestic Competition (Section 4.4)}

As discussed in section 4.4 of the paper, many international students might have regional preferences and prefer studying in one country over doing so in another for a variety of reasons, including cultural preferences, language skills and personal relationships. In this case, universities within a country are in fiercer competition with each other than universities in different countries. Also, public universities compete with private universities in many countries, and governments find it easier to influence decisions of public universities. We take up these issues by analysing now domestic competition between a public university and a private one, assuming that $N$ international students intend to study in the country where the two universities are located. While the government can control the education quality and tuition fee of the public university, it has no sway over the decisions of the private university. Otherwise, the universities compete in education quality and tuition fees as they did in the previous sections. This analysis complements our preceding analysis of international competition.

In principle, there are two possible equilibria, one in which the public university provides a higher education quality and one in which the private university does so (unless the objective functions of the two different universities are too 'asymmetric', in which case only one of the two equilibria might exist). We focus now on the case in which the quality of education is higher at the public university than at the private rival. Adjusting the objective functions of the public and the private university to this new setting, we obtain

$$
\begin{gathered}
R_{1}^{P}=\hat{a} N\left[t_{1}-c\left(q_{1}\right)\right]-F\left(q_{1}\right) \\
R_{2}^{S}=(1-\hat{a}) N\left\{\tau p\left[\underline{w}+\frac{1}{2}(1+\hat{a}) q_{2}\right]+t_{2}-c\left(q_{2}\right)\right\}+\hat{a} N \tau p\left(\underline{w}+\frac{1}{2} \hat{a} q_{1}\right)-F\left(q_{2}\right),
\end{gathered}
$$

where the superscripts $P$ and $S$ stand for 'private' and 'state' (i.e., public). For simplicity, we set $\lambda=0$, which reduces the objective function of the private university to (70). Objective function (71) contains all expected tax revenues that will arise in this country, irrespective of whether the tax payer graduated at the public or private 
university. However, it only includes the tuition fee revenues and education costs of the public university. Thus, the government aims at maximising the contribution of international students to the public budget (including the budget of the public university).

\section{Quality and Tuition Fee Competition Revisited 2}

Let us again first consider the tuition fee competition in the second stage, taking into account that the threshold value (3) still determines the demand of the international pool of talent for the two universities. The universities set their tuition fees simultaneously and non-cooperatively, leading to the first-order conditions

$$
\frac{\partial R_{1}^{P}}{\partial t_{1}}=N\left[\frac{\partial \hat{a}}{\partial t_{1}}\left(t_{1}-\alpha q_{1}\right)+\hat{a}\right]=0 \quad \Leftrightarrow \quad t_{1}^{P S}=\varrho\left(q_{2}-q_{1}\right) \hat{a}+\alpha q_{1}
$$

and

$$
\begin{aligned}
\frac{\partial R_{2}^{S}}{\partial t_{2}} & =N\left\{-\frac{\partial \hat{a}}{\partial t_{2}}\left[p \tau \hat{a}\left(q_{2}-q_{1}\right)+t_{2}-\alpha q_{2}\right]+(1-\hat{a})\right\}=0 \\
& \Leftrightarrow \quad t_{2}^{P S}=[\varrho(1-\hat{a})-p \tau \hat{a}]\left(q_{2}-q_{1}\right)+\alpha q_{2}
\end{aligned}
$$

where the superscript $P S$ stands for variables in the case of domestic competition between a private and a public (state) university. Inserting threshold value (3) into (72) and (73) and rearranging the resulting terms yield the threshold level

$$
\hat{a}^{P S}=\frac{\alpha+\varrho}{p \tau+3 \varrho}
$$

and the tuition fee differential

$$
\Delta t^{P S}:=t_{2}^{P S}-t_{1}^{P S}=\Omega^{P S}(p, \rho) \Delta q, \quad \text { where } \quad \Omega^{P S}(p, \rho)=\frac{\varrho(\alpha+\varrho)}{p \tau+3 \varrho} .
$$

The corresponding tuition fees are given by

$$
\begin{aligned}
& t_{1}^{P S}\left(q_{1}, q_{2}\right)=\frac{\varrho\left[\varrho \Delta q+\alpha\left(q_{2}+2 q_{1}\right)\right]+\alpha p \tau q_{1}}{p \tau+3 \varrho}, \\
& t_{2}^{P S}\left(q_{1}, q_{2}\right)=\frac{\varrho\left[2 \varrho \Delta q+\alpha\left(q_{1}+2 q_{2}\right)\right]+\alpha p \tau q_{1}}{p \tau+3 \varrho} .
\end{aligned}
$$

Second, we explore the quality competition in the first stage. Using the solutions (74), (76), and (77), we can calculate the derivatives

$$
\frac{\partial R_{1}^{P}}{\partial q_{1}}=\hat{a}^{P S} N\left(\frac{\partial t_{1}^{P S}}{\partial q_{1}}-\alpha\right)-\frac{\partial F}{\partial q_{1}}=-N \varrho\left(\hat{a}^{P S}\right)^{2}-\frac{\partial F}{\partial q_{1}}<0,
$$


implying the optimal quality level $q_{1}^{P S}=0$, and

$$
\begin{aligned}
\frac{\partial R_{2}^{S}}{\partial q_{2}} & =\left(1-\hat{a}^{P S}\right) N\left(\frac{p \tau}{2}\left(1+\hat{a}^{P S}\right)+\frac{\partial t_{2}^{P S}}{\partial q_{2}}-\alpha\right)-\frac{\partial F}{\partial q_{2}} \\
& =\frac{N}{2}(p \tau+2 \varrho)\left(1-\hat{a}^{P S}\right)^{2}-\frac{\partial F}{\partial q_{2}}=0
\end{aligned}
$$

implicitly determining the quality level $q_{2}^{P S}>0$.

Jointly, the threshold level (74), the tuition fees (76) and (77), the first-order condition (79) and the quality level $q_{1}^{P S}=0$ determine a local equilibrium with $q_{2}^{P S}>q_{1}^{P S}=0$ and $t_{2}^{P S}>t_{1}^{P S}$. In the scenario in which the public university provides the high-quality education, it attracts the brightest students, i.e., those with $a \in\left[\hat{a}^{P S}, 1\right]$, whereas the private university takes the other students.

Comparing these equilibrium values with those in the case of international public competition reveals astonishing similarities and a few differences (see (8)-(13)). The levels of education quality, the quality and tuition fee differentials and the threshold level $\hat{a}^{P S}$ are the same as the ones in the case of international public competition. That is, $q_{1}^{P S}=q_{1}^{*}, q_{2}^{P S}=q_{2}^{*}, \Delta q^{P S}=\Delta q^{*}, \Delta t^{P S}=\Delta t^{*}$ and $\hat{a}^{P S}=\hat{a}^{*}$. Both tuition fees $t_{1}^{P S}$ and $t_{2}^{P S}$ exceed their counterparts $t_{1}^{*}$ and $t_{2}^{*}$ by $p \tau \underline{w}$. That is, $t_{1}^{P S}=$ $\left[\rho(\alpha+\rho) q_{2}^{P S}\right] /(p \tau+3 \rho)=t_{1}^{*}+p \tau \underline{w}$ and $t_{2}^{P S}=\left[2 \rho(\alpha+\rho) q_{2}^{P S}\right] /(p \tau+3 \rho)=t_{2}^{*}+$ $p \tau \underline{w}$.

The intuition for this outcome is as follows: Compared to the situation under international public competition, the negative effects of raising the tuition fee of the public university are cushioned. Now, students who switch from the public to the private university to avoid such higher fees still stay in the country and end up as domestic tax payers with probability $p$. Their tax payments will be lower if the private university provides a lower education quality, but they will not vanish altogether. As a result, the public university charges a higher tuition fee; and the private university follows suit, since the private university (ignoring the fiscal benefits generated by international students) anyway tends to charge higher tuition fees, and since tuition fees are strategic complements. This evenly increases the tuition fees without affecting the tuition fee differential and the allocation of the students across the two universities.

How does domestic competition change the incentive for the public university to invest in education quality? On the one hand, attracting another student means that this student pays $p \tau \underline{w}$ more in tuition fees under domestic competition than under international public competition. This strengthens the incentive to raise education quality. On the other hand, the gain in terms of additional tax payments is $p \tau \underline{w}$ lower under domestic competition, as this is the expected amount the students pay 
in taxes even if they graduate at the private university with quality level $q_{1}^{P S}=0$. As the two opposing effects cancel each other out exactly, the net incentives to invest in education quality are the same under domestic and international competition, and so are thus the equilibrium quality levels $q_{2}^{P S}$ and $q_{2}^{*}$.

\section{Competition in a Changing Environment Revisited 2}

As a result of the strong similarities between the equilibrium in the case of international public competition and the one in the case of domestic competition between a public and a private university, it is no surprise that the effects of socioeconomic changes on the education quality levels, the quality and tuition fee differentials and the allocation of students are the same under these two forms of competition. Formally, this conclusion follows from the fact that $q_{2}^{P S}=q_{2}^{*}$ implies $\partial q_{2}^{P S} / \partial p=\partial q_{2}^{*} / \partial p, \partial q_{2}^{P S} / \partial \gamma=\partial q_{2}^{*} / \partial \gamma, \partial q_{2}^{P S} / \partial N=\partial q_{2}^{*} / \partial N$, and that $\Delta t^{P S}=\Delta t^{*}$ implies $\partial \Delta t^{P S} / \partial p=\partial \Delta t^{*} / \partial p, \partial \Delta t^{P S} / \partial \gamma=\partial \Delta t^{*} / \partial \gamma, \partial \Delta t^{P S} / \partial N=\partial \Delta t^{*} / \partial N$, etc.

Similarly, the effects of a change in the income in ROW and the size of the pool of talent on the tuition fees are the same in the current extension as in the basic model in the paper. Formally, $t_{i}^{P S}=t_{i}^{*}+p \tau \underline{w}$ implies $\partial t_{i}^{P S} / \partial \gamma=\partial\left(t_{i}^{*}+p \tau \underline{w}\right) / \partial \gamma=\partial t_{i}^{*} / \partial \gamma$ and $\partial t_{i}^{P S} / \partial N=\partial\left(t_{i}^{*}+p \tau \underline{w}\right) / \partial N=\partial t_{i}^{*} / \partial N$. Moreover, inserting $q_{1}=0$ into (76) and (77) gives the relationship $t_{2}^{P S}=2 t_{1}^{P S}$, leading to $\Delta t^{P S}=t_{2}^{P S}-t_{1}^{P S}=t_{1}^{P S}$. Then, $d t_{2}^{P S} / d k=2 d t_{1}^{P S} / d k=2 d \Delta t^{P S} / d k, k=p, \gamma, N$. That is, both tuition fees increase or decrease along with the tuition fee differential, as the socioeconomic environment changes. Thus, an increase in the ROW income parameter or the size of the pool of talent raises not only the tuition fee differential but also both tuition fees. Also, both tuition fees respond as ambiguous to changes in the stay rate as the tuition fee differential does. Consequently, all conclusions stated in propositions 1 to 3 and corollary 1 carry over to the case of domestic competition without qualifications. There are no qualitative changes of the comparative statics results.

The situation is slightly more complicated in the corresponding equilibrium in which the private university is the high-quality provider. Such an equilibrium can exist under certain circumstances even if $\lambda=0$. However, even in this equilibrium, if it exists, the tuition fee differential $\Delta t$ and threshold value $\hat{a}$ are given by (10) and (11), which characterise the corresponding variables in the case of international public competition. Also, the comparative statics conclusions in propositions 1 to 3 with respect to the levels of education quality, the quality and tuition fee differential and the allocation of students across the two university are qualitatively the same. In this sense, our comparative statics conclusions are fairly robust across different forms of competition. 


\section{B.3 Domestic Students (Section 6)}

In section 6 of the paper, we argue that including domestic students into the analysis provides a more comprehensive picture of the competition for the international pool of talent, especially as universities often invest in 'general' education quality, i.e., in quality that benefits both domestic and foreign students in the same way. We now give a more detailed derivation of the results presented in section 6 of the paper without, however, repeating all the basic assumptions of this variant of the model, as they are already stated in the paper.

Recall from the paper that there is a given pool of domestic talent of size $D$ in each country, and that this pool is characterised by the same uniform ability distribution which also describes the pool of international students. However, these domestic students are internationally immobile. Only general (and not specific) education quality, denoted by $q_{i}^{D}$, is provided to both domestic and foreign students. As a preliminary step, let us consider the optimal education policy of each country in the case in which only domestic students exist. We look at this case first because we want to discover under which conditions all potential domestic students choose to attend the local university.

The wage of non-graduates is normalised to zero, implying that natives enrol at their domestic university if graduate wage $\underline{w}+a q_{i}$ exceeds the tuition fee for domestic students. Then, with a domestic pool of talent only, each government's objective function, denoted by the superscript Donly, contains the wage sum of domestic graduates and the education costs, and is given by

$$
R^{\text {Donly }}=\left(1-\hat{a}^{D}\right) D\left\{\left[\underline{w}+\frac{1}{2}\left(1+\hat{a}^{D}\right) q\right]-c(q)\right\}-F(q),
$$

where $\hat{a}^{D}$ stands for the threshold ability level of the domestic students (we suppress the country index $i$ for the time being). As already stated in the paper, tuition fees for domestic students and taxes paid by natives are welfare-neutral and thus do not enter the objective function. As a result, the tuition fees for domestic students are simply designed such that the optimal share of the domestic pool of talent receives higher education. Note that $\hat{a}^{D}=0$ implies that all domestic students attend university; thus, the market for domestic students is fully covered. As stated in the paper, we are interested in exactly this case, where all potential domestic students are enrolled, and where the two countries compete for the international pool of students only. This simple setting already allows us to sketch some implications of the interplay between the competition for the international pool of talent and a domestic student body. We first discuss the condition under which the case $\hat{a}^{D}=0$ emerges as optimal 
outcome. (Obviously, there always exists a set of tuition fee levels that guarantees $\hat{a}^{D}=0$.)

Taking the derivative of $R^{\text {Donly }}$ with respect to $\hat{a}^{D}$ yields

$$
\frac{\partial R^{D o n l y}}{\partial \hat{a}^{D}}=-D\left(\underline{w}+\hat{a}^{D} q-\alpha q\right) \text {, implying }\left.\frac{\partial R^{\text {Donly }}}{\partial \hat{a}^{D}}\right|_{\hat{a}^{D}=0} \leq 0 \Leftrightarrow \underline{w} \geq \alpha q .
$$

Thus, each governments will implement a tuition fee such that all potential domestic students will enrol (i.e., $\hat{a}^{D}=0$ ) if the condition $\underline{w} \geq \alpha q$, the condition for a fully covered market for domestic students, is fulfilled. (Note that $\partial^{2} R^{D o n l y} / \partial\left(\hat{a}^{D}\right)^{2}=$ $-D q \leq 0$ for $q \geq 0$, which guarantees that $\hat{a}^{D}=0$ is indeed optimal if $\underline{w} \geq \alpha q$.)

Next, let us discuss the optimal level of education quality in the absence of international students. The derivative of $R^{\text {Donly }}$ with respect to the general quality level $q$,

$$
\frac{\partial R^{\text {Donly }}}{\partial q}=\left(1-\hat{a}^{D}\right) D\left[\frac{1}{2}\left(1+\hat{a}^{D}\right)-\alpha\right]-\frac{\partial F}{\partial q},
$$

can only be positive at $q=0$ if $\alpha<\frac{1}{2}\left(1+\hat{a}^{D}\right)$ or, for $\hat{a}^{D}=0, \alpha<1 / 2$. Only then can a positive education quality result, and we assume that $\alpha<1 / 2$ is indeed satisfied. In fact, for a sufficiently large $\underline{w}$ and a sufficiently small $\alpha$, the market for domestic students is fully covered in optimum, which can be achieved by setting the tuition fee for domestic students such that it falls short of the net graduate base salary $(1-\tau) \underline{w}$, and the optimal quality level $q^{\text {Donly }}$ is positive and characterised by $\partial R^{\text {Donly }} / \partial q=0$ (assuming, as we have implicitly done before, that $\partial F(0) / \partial q$ is also sufficiently small; note that the second-order condition $\partial R^{\text {Donly }} / \partial q=-\partial^{2} F / \partial q^{2}<0$ is fulfilled).

\section{Quality and Tuition Fee Competition Revisited 3}

We now add international students to the model and, as mentioned above, consider general education quality, which affects both foreign and domestic students in the same way. We assume that the condition $\underline{w} \geq \alpha q$ is satisfied, meaning that all domestic students attend university when each government optimally chooses the tuition fees for its domestic students (adding international students does not affect this condition).

The governments of the two countries again enter tuition fee and quality competition for foreign students, whose demand is still characterised by threshold value (3). Rewriting the governments' objective functions (18) in an extended form gives

$$
R_{1}^{D}=D\left[\left(\underline{w}+\frac{1}{2} q_{1}^{D}\right)-c\left(q_{1}^{D}\right)\right]+\hat{a} N\left\{\tau p\left[\underline{w}+\frac{1}{2} \hat{a} q_{1}^{D}\right]+t_{1}-c\left(q_{1}^{D}\right)\right\}-F\left(q_{1}^{D}\right),
$$




$$
\begin{aligned}
R_{2}^{D} & =D\left[\left(\underline{w}+\frac{1}{2} q_{2}^{D}\right)-c\left(q_{2}^{D}\right)\right] \\
& +(1-\hat{a}) N\left\{\tau p\left[\underline{w}+\frac{1}{2}(1+\hat{a}) q_{2}^{D}\right]+t_{2}-c\left(q_{2}^{D}\right)\right\}-F\left(q_{2}^{D}\right) .
\end{aligned}
$$

Comparing these objective function with (6) and (7) yields $R_{i}^{D}=$ $D\left[\left(\underline{w}+(1 / 2) q_{i}^{D}\right)-\alpha q_{i}^{D}\right]+R_{i}$. Therefore, as $\partial D\left[\left(\underline{w}+(1 / 2) q_{i}^{D}\right)-\alpha q_{i}^{D}\right] / \partial t_{i}=0$ holds, $\partial R_{i}^{D} / \partial t_{i}=\partial R_{i} / \partial t_{i}$ results. (Recall that $t_{i}$ still stands for the tuition fees for international students, which can differ from those for domestic students.) Thus, the first-order conditions in the second stage (tuition fee competition) are identical in the cases with and without domestic students, and so are the tuition fees, the tuition fee differential and the allocation of students. Hence, the outcome of the tuition fee competition is still fully described by (8), (9), (10) and (11).

Next, let us consider the quality competition in the first stage. The equilibrium quality levels are characterised by the conditions (19) and (20) in the paper. Comparing the first-order condition (20) with (13) reveals that $\partial R_{2}^{D} / \partial q_{2}=$ $D(1 / 2-\alpha)+\partial R_{2} / \partial q_{2}>\partial R_{2} / \partial q_{2}$ for $\alpha<1 / 2$, which implies $q_{2}^{D}>q_{2}^{*}$ for $\alpha<1 / 2$. Similarly, $\partial R_{2}^{D} / \partial q_{2}=(N / 2)(p \tau+2 \varrho)(1-\hat{a})^{2}+\partial R_{2}^{\text {Donly }} / \partial q_{2}>\partial R_{2}^{\text {Donly }} / \partial q_{2}$ yields $q_{2}^{D}>q_{2}^{\text {Donly }}$.

Furthermore, inspection of condition (19) shows that, for $\alpha<1 / 2$, $\partial R_{1}^{D} /\left.\partial q_{1}\right|_{q_{1}=0} \gtreqless 0 \Leftrightarrow D \gtreqless\left[\hat{a}^{2}(p \tau+2 \varrho) N-2\left(\partial F_{1}(0) / \partial q_{1}\right)\right] /(1-2 \alpha)$, leading to

$$
q_{1}^{D}\left\{\begin{array}{lll}
=0=q_{1}^{*} & \text { if } & D \leq \frac{\hat{a}^{2}(p \tau+2 \varrho) N-2\left(\partial F_{1}(0) / \partial q_{1}\right)}{1-2 \alpha} \\
>0=q_{1}^{*} & \text { if } & D>\frac{\hat{a}^{2}(p \tau+2 \varrho) N-2\left(\partial F_{1}(0) / \partial q_{1}\right)}{1-2 \alpha}
\end{array}\right.
$$

The role of the sizes of domestic and foreign student cohorts can immediately be inferred from (85). For $\alpha<1 / 2$, educational quality in the low-quality country will be positive and thus higher than in the case without domestic students if $D$ is sufficiently large or $N$ is sufficiently small. Otherwise, the educational quality in this country will be zero, as it will also be if $\alpha \geq 1 / 2$.

\section{Competition in a Changing Environment Revisited 3}

As a final step, we will now show how including domestic students into the analysis affects the way changes in the socio-economic environment shape international competition. We focus on the scenario with $q_{1}^{D}>0$ because our propositions 1 to 3 and corollary 1 would trivially remain valid if $q_{1}^{D}=0$ resulted. Importantly, as the allocation of students is still characterised by (11), all comparative statics results of propositions 1 to 3 with respect to this threshold level remain valid without qualification. 
Regarding the other equilibrium values, we begin by investigating the effects of the stay rate on the educational quality in the two countries. Consider first the effect on quality $q_{1}^{D}$. Since the income effect in (19) is independent of $p$, the impact of the stay rate on educational quality runs through the competitive effect only, and comparative statics leads to

$$
\frac{d q_{1}^{D}}{d p} \gtreqless 0 \Leftrightarrow \frac{d^{2} R_{1}^{D}}{d q_{1}^{D} d p}=-\frac{1}{2} \hat{a} N\left[\left(\tau+2 \frac{\partial \varrho}{\partial p}\right) \hat{a}+2(p \tau+2 \varrho) \frac{d \hat{a}}{d p}\right] \gtreqless 0 .
$$

As $\partial \varrho / \partial p \geq 0$ (see (32)) and $d \hat{a} / d p<0$ (see (33)) work into opposite directions, the sign of the term $d q_{1}^{D} / d p$ is unclear. We can show that $d q_{1} / d p<0$ results in the scenario with $\gamma=0$ (implying $\partial \varrho / \partial p=1-\tau$ ) and $\alpha=0$, while $d q_{1} / d p>0$ holds in the special case with $\tau_{R O W}=\tau$ and $\gamma=1$ (implying $\partial \varrho / \partial p=0$ ).

Regarding country 2 , from (20) follows

$$
\frac{d q_{2}^{D}}{d p}>0 \Leftrightarrow \frac{d^{2} R_{2}^{D}}{d q_{2}^{D} d p}=\frac{1}{2}(1-\hat{a}) N\left[(1-\hat{a})\left(\tau+2 \frac{\partial \varrho}{\partial p}\right)-2(p \tau+2 \varrho) \frac{d \hat{a}}{d p}\right]>0,
$$

where $\partial \varrho / \partial p \geq 0$ (see again (32)) and $d \hat{a} / d p<0$ (see again (33)) yield the last inequality sign (see (36), which is completely in line with (87)). That is, the educational quality in country 2 unambiguously increases with the stay rate, as it does in the basic model without domestic students. Since, however, the effect of the stay rate on $q_{1}^{D}$ is ambiguous, its impact on the quality differential $\Delta q^{D}$ cannot be determined without further specification. Calculations with the quadratic fixed cost function $F\left(q_{i}\right)=(1 / 2) q_{i}^{2}$ indicate that $d \Delta q^{D} / d p<0$ is only possible if the cost parameter $\alpha$ is rather large, which implies a threshold value $\hat{a}$ that is fairly close to one. Conversely, the quality differential $\Delta q^{D}$ increases with the stay rate $p$ for a small cost parameter $\alpha$, at least in the case of this quadratic fixed cost function. Then, propositions 1 to 3 and corollary 1 remain valid.

The impact of the stay rate on the tuition fee differential is already ambiguous in the basic model of the paper, and the ambiguity of the sign of $d \Delta q^{D} / d p$ further adds to the ambiguity of the sign of the term $d \Delta t / d p$, as comparing (38) with the following derivative shows:

$$
\begin{aligned}
\frac{d \Delta t}{d p} & =\Omega \frac{d \Delta q^{D}}{d p}+\Delta q^{D}\left\{\frac{d \Omega}{d p}+\frac{\partial \Omega}{\partial \varrho} \frac{\partial \varrho}{\partial p}\right\} \\
& =\Omega \frac{\Delta q^{D}}{p}\{\underbrace{\frac{d \Delta q^{D}}{d p} \frac{p}{\Delta q^{D}}}_{:=\varepsilon_{\Delta q^{D}, p} \gtrless 0}+\underbrace{\frac{\partial \Omega}{\partial p} \frac{p}{\Omega}}_{:=\varepsilon_{\Omega, p}<0}+\underbrace{\frac{\partial \Omega}{\partial \varrho} \frac{\varrho}{\Omega}}_{:=\varepsilon_{\Omega, \varrho}>0} \cdot \underbrace{\frac{\partial \varrho}{\partial p} \frac{p}{\varrho}}_{:=\varepsilon_{\varrho, p} \geq 0}\} \gtreqless 0 .
\end{aligned}
$$


Next, we analyse the impact of an increase in the income in ROW. The effect of a higher income in the rest of the world on the educational quality in country 1 is ambiguous, as shown by

$$
\frac{d q_{1}^{D}}{d \gamma} \gtreqless 0 \Leftrightarrow \frac{d^{2} R_{1}^{D}}{d q_{1}^{D} d \gamma} \gtreqless 0 \Leftrightarrow-3 \varrho(p \tau+\varrho-\alpha)-p \tau(p \tau-2 \alpha) \gtreqless 0 .
$$

Inspection of (90) reveals that the term $d q_{1}^{D} / d \gamma$ becomes negative for small values of the cost parameter $\alpha$ (e.g., for $\alpha=0$ ), while $d q_{1}^{D} / d \gamma$ is positive for large values of $\alpha$ (e.g., $\alpha \rightarrow p \tau+2 \varrho$, implying $\hat{a} \rightarrow 1$ ). That is, the educational quality in country 1 decreases (increases) with the ROW income parameter $\gamma$ if the cost parameter $\alpha$ is small (large). By contrast, the impact of the income parameter $\gamma$ on educational quality $q_{2}^{D}$ is clear-cut:

$$
\frac{d q_{2}^{D}}{d \gamma}>0 \Leftrightarrow \frac{d^{2} R_{2}^{D}}{d q_{2}^{D} d \gamma}>0 \Leftrightarrow 3 \varrho p \tau+6 \varrho^{2}+2 \alpha p \tau+3 \alpha \varrho>0,
$$

where the last inequality, which is the same as the one in the case without domestic students (see (42)), always holds. Thus, the education quality in country 2 always increases with the ROW income parameter $\gamma$. Nevertheless, the ambiguity of the sign of the term $d q_{1}^{D} / d \gamma$ carries over to the sign of the term $d \Delta q^{D} / d \gamma$. The quality differential $\Delta q^{D}$ increases with the parameter $\gamma$ if the education cost $\alpha$ is sufficiently small (as quality $q_{2}^{D}$ increases and quality $q_{1}^{D}$ decreases in this case), while the differential $\Delta q^{D}$ can decline if the the parameter $\alpha$ is sufficiently large (as we can show for the case of a quadratic fixed cost function, the increase in quality $q_{1}^{D}$ can exceed the rise in quality $q_{2}^{D}$ ).

Again, the ambiguity of $d \Delta q^{D} / d \gamma$ makes the effect of $\gamma$ on the tuition fee differential $\Delta t^{D}$ ambiguous too, since

$$
\frac{d \Delta t}{d \gamma}=\frac{\partial \Omega^{D}}{\partial \rho} \frac{\partial \rho}{\partial \gamma} \Delta q+\Omega^{D} \frac{d \Delta q^{D}}{d \gamma} \gtreqless 0,
$$

where the first-term of the right-hand side of the equation sign is positive, which follows from $(39)$ and $\partial \varrho / \partial \gamma=(1-p)\left(1-\tau_{R O W}\right) \geq 0$ (see $\left.(1)\right)$. If the term $d \Delta q^{D} / d \gamma$ were sufficiently negative, then $d \Delta t / d \gamma$ could be negative as well. Without further calculations, we cannot exclude this case. However, for sufficiently small education costs $\alpha$, the quality differential $\Delta q^{D}$ increases with the ROW income parameter $\gamma$ for sure, and so does the tuition fee differential $\Delta t$, all in line with proposition 2 .

Finally, consider the effect of the size of the talent pool on educational quality. Comparative statics reveals

$$
\frac{d q_{1}^{D}}{d N}<0 \Leftrightarrow \frac{d^{2} R_{1}^{D}}{d q_{1}^{D} d N}<0 \Leftrightarrow-\frac{1}{2} \hat{a}^{2}(p \tau+2 \varrho)<0,
$$




$$
\frac{d q_{2}^{D}}{d N}>0 \Leftrightarrow \frac{d^{2} R_{2}^{D}}{d q_{2}^{D} d N}>0 \Leftrightarrow \frac{1}{2}(1-\hat{a})^{2}(p \tau+2 \varrho)>0,
$$

where (94) is completely in line with (47). As $\partial q_{1}^{D} / \partial N<0$ and $\partial q_{2}^{D} / \partial N>0$, $d \Delta q^{D} / d N>0$ results, which in turn implies

$$
\frac{\partial \Delta t^{D}}{\partial N}=\Omega^{D} \frac{d \Delta q^{D}}{d N}>0
$$

(compare with (48)). The conclusions about the quality and tuition fee differentials are identical to those reached in proposition 3 .

\section{References}

Beine, M., Docquier, F. and H. Rapoport (2008). Brain Drain and Human Capital Formation in Developing Countries: Winners and Losers, The Economic Journal 118, 631-652.

Beine, M., Noël, R. and L. Ragot (2014). The Determinants of International Mobility of Students, Economics of Education Review 41, 40â€"54.

Boadway, R., Marceau N. and M. Marchand (1996). Issues in Decentralizing the Provision of Education, International Tax and Public Finance 3, 311-327.

Büttner, T. and R. Schwager (2004). Regionale Verteilungseffekte der Hochschulfinanzierung und ihre Konsequenzen, in: Franz, W., Ramser, H. J., Stadler, M. (eds.), Bildung, 33. Wirtschaftswissenschaftliches Seminar Ottobeuren, Tübingen, 251-278.

Chaloff, J. and G. Lemaitre (2009). Managing Highly-skilled Labour Migration: A Comparative Analysis of Migration Policies and Challenges in OECD Countries, OECD Social, Employment and Migration Working Paper 79.

Cigno, A. and A. Luporini (2009). Scholarships or Student Loans? Subsidizing Higher Education in the Presence of Moral Hazard, Journal of Public Economic Theory 11, 55-87.

De Fraja, G. and E. Iossa (2002). Competition among Universities and the Emergence of the Elite Institution, Bulletin of Economic Research 54, 257-293.

Del Rey, E. (2001). Economic Integration and Public Provision of Education, Empirica 28, 203-218. 
Demange, G. and R. Fenge (2010). Competition in the Quality of Higher Education: The Impact of Students' Mobility, Working Paper 2010-27, Paris School of Economics.

Dos Santos, M.D. and F. Postel-Vinay (2003). Migration as a Source of Growth: The Perspective of a Developing Country, Journal of Population Economics $16,161-175$.

Dreher, A. and P. Poutvaara (2011). Foreign Students and Migration to the United States, World Development 39, 1294-1307.

Eggert, W., Krieger, T. and V. Meier (2010). Education, Unemployment and Migration, Journal of Public Economics 94, 354-362.

Finn, M. (2003). Stay Rates of Foreign Doctorate Recipients from U.S. Universities, Oak Ridge Institute for Science and Education, Oak Ridge.

Gabszewicz, J.J. and J.-F. Thisse (1979). Price Competition, Quality and Income Disparities, Journal of Economic Theory 20, 340-395.

Gérard, M. (2007). Financing Bologna: Which Country will Pay for Foreign Students?, Education Economics 15, 441-454.

Grazzini, L., Luporini, A. and A. Petretto (2010). Competition between State Universities, Working Paper 02/2010, Dipartimento die Scienze Economiche, Università degli Studi di Firenze.

Haupt, A., Krieger, T. and T. Lange (2014). Education Policy, Student Migration, and Brain Gain, in: Gérard, M. and S. Uebelmesser (eds.), The Mobility of Students and the Highly Skilled: Implication for Education Financing and Economic Policy, MIT Press, Cambridge/MA, 287-319.

Hoyt, W. and R. Jensen (2001). Product Differentiation and Public Education, Journal of Public Economic Theory 3, 69-93.

Hübner, M. (2012). The Welfare Effects of Discriminating between In-state and Out-of-state Students, Regional Science and Urban Economics 42, 364-374.

Kemnitz, A. (2007a). University Funding Reform, Competition, and Teaching Quality, Journal of Institutional and Theoretical Economics 163, 356-378.

Kemnitz, A. (2007b). Educational Federalism and the Quality Effects of Tuition Fees, Dresdner Discussion Paper in Economics 08/07, Dresden University of Technology. 
Krieger, T. and T. Lange (2010). Education Policy and Tax Competition with Imperfect Student and Labor Mobility, International Tax and Public Finance $17,587-606$.

Lange, T. (2009). Public Funding of Higher Education when Students and Skilled Workers are Mobile, FinanzArchiv/Public Finance Analysis 65, 178-199.

Lange, T. (2013). Return Migration of Foreign Students and Non-Resident Tuition Fees, Journal of Population Economics 26, 703-718.

OECD (2011). Education at a Glance, OECD, Paris.

OECD (2014). Education at a Glance, OECD, Paris.

OECD (2015). Education at a Glance, OECD, Paris.

Rosenzweig, M. (2006). Global Wage Differences and International Student Flows, in: Collins, S.M. and C. Graham (eds.): Brookings Trade Forum 2006: Global Labor Markets?, Brookings Press, 57-86.

Rosenzweig, M. (2008). Higher Education and International Migration in Asia: Brain Circulation, in: Lin, J.Y. and B. Pleskovic (eds.): Higher Education and Development, The World Bank, Washington D.C., 59-84.

Shaked, A. and J. Sutton (1982). Relaxing Price Competition Through Product Differentiation, Review of Economic Studies 49, 3-13.

Stark, O., Helmenstein, C. and A. Prskawetz (1997). A Brain Gain with a Brain Drain, Economics Letters 55, 227-234.

Stark, O., Helmenstein, C. and A. Prskawetz (1998). Human Capital Depletion, Human Capital Formation, and Migration: A Blessing or a 'Curse'?, Economics Letters 60, 363-367.

Stark, O. and Y. Wang (2002). Inducing Human Capital Formation Migration as a Substitute for Subsidies, Journal of Public Economics 86, 29-46.

Vidal, J.-P. (1998). The Effect of Emigration on Human Capital Formation, Journal of Population Economics 11, 589-600.

Zissimos, B. and M. Wooders (2008). Public Good Differentiation and the Intensity of Tax Competition, Journal of Public Economics 92, 1105-1121. 